\title{
C1 Chemistry for the Production of Ultra-Clean Liquid Transportation Fuels and Hydrogen
}

\author{
Semi-annual six-month report \\ Research conducted October 1, 2002-March 31, 2003 \\ DOE Cooperative Agreement No. DE-FC26-02NT4159 \\ Prepared by the Consortium for Fossil Fuel Science \\ Gerald P. Huffman, Director \\ CFFLS / University of Kentucky \\ 533 S. Limestone Street, Suite 107 \\ Lexington, KY 40506 \\ Phone: (859) 257-4027 \\ FAX: (859) 257-7215 \\ E-mail: huffman@engr.uky.edu
}

Consortium for Fossil Fuel Science

University of Kentucky

West Virginia University

University of Pittsburgh

University of Utah

Auburn University

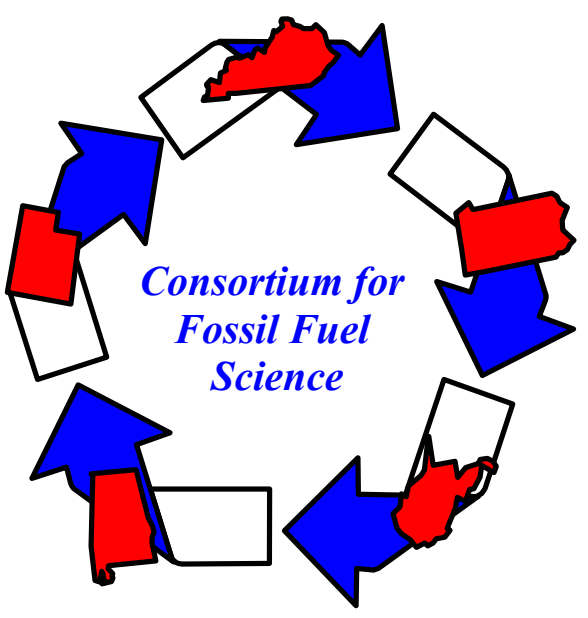


This report was prepared as an account of work sponsored by an agency of the United States Government. Neither the United States Government nor any agency thereof, nor any of their employees, makes any warranty, express or implied, or assumes any legal liability or responsibility for the accuracy, completeness, or usefulness of any information, apparatus, product, or process disclosed, or represents that its use would not infringe privately owned rights. Reference herein to any specific commercial product, process, or service by trade name, trademark, manufacturer, or otherwise does not necessarily constitute or imply its endorsement, recommendation, or favoring by the United States Government or any agency thereof. The views and opinions of authors expressed herein do not necessarily state or reflect those of the United States Government or any agency thereof. 
Table of Contents

\begin{tabular}{|l|c|}
\hline \multicolumn{1}{|c|}{ Topic } & Page \\
\hline Abstract & 4 \\
\hline Investigation of Fischer-Tropsch Mechanisms Using Probe Molecules & 5 \\
\hline Diesel and Jet Fuel from Fischer-Tropsch Wax & 7 \\
\hline Sol-Gel Catalyst F-T Synthesis of Diesel Fuel & 9 \\
\hline Organometallic precursors for F-T catalysts & 12 \\
\hline Silicon-29 NMR studies of xerogel supported F-T catalysts & 14 \\
\hline $\begin{array}{l}\text { On-line GC/MS Analysis of Fischer Tropsch Reaction Products; Investigation and } \\
\text { Evaluation of Metal Carbonyl Formation Processes }\end{array}$ & 16 \\
\hline Supercritical Fluids as Reaction Medium for Fischer-Tropsch Synthesis & 21 \\
\hline $\begin{array}{l}\text { Microporous Shape-Selective Catalysts and Processes for Ethylene, Propylene and other } \\
\text { Value-Added Products via C-1 Chemistry }\end{array}$ & 23 \\
\hline Dry Reforming of Methane to Synthesis Gas with Tungsten Carbide Catalyst & 25 \\
\hline Synthesis of Hydrocarbons and Alcohols from Syngas & 28 \\
\hline Hydrogen production by catalytic decomposition of ethane and propane & 31 \\
\hline XAFS and Mössbauer Investigation of Catalysts & 34 \\
\hline $\begin{array}{l}\text { Science behind Catalysis in C1 Reactions: Catalyst characterization and } \\
\text { determination of active species }\end{array}$ & 37 \\
\hline
\end{tabular}




\title{
C1 Chemistry for Production of Ultra-Clean Liquid Transportation Fuels and Hydrogen
}

Contact: Gerald P. Huffman, Director, Consortium for Fossil Fuel Science, University of Kentucky, Suite 107 Whalen Building, 533 S. Limestone St., Lexington, KY 40506-0043

(859) 257-4027; FAX: (859)257-7215; huffman@engr.uky.edu

\begin{abstract}
Faculty and students from five universities - the University of Kentucky, University of Pittsburgh, University of Utah, West Virginia University, and Auburn University - are collaborating in a research program to develop $\mathrm{C} 1$ chemistry processes to produce ultra-clean liquid transportation fuels and hydrogen, the zero-emissions transportation fuel of the future. The feedstocks contain one carbon atom per molecular unit. They include synthesis gas (syngas), a mixture of carbon monoxide and hydrogen produced by coal gasification or reforming of natural gas, methane, methanol, carbon dioxide, and carbon monoxide. An important objective is to develop $\mathrm{C} 1$ technology for the production of transportation fuel from domestically plentiful resources such as coal, coalbed methane, and natural gas. An Industrial Advisory Board with representatives from Chevron-Texaco, Eastman Chemical, ConocoPhillips, Energy International, the Department of Defense, and Tier Associates provides guidance on the practicality of the research. The current report presents results obtained in this research program during the first six months of the subject contract (DE-FC26-02NT-4159), from October 1, 2002 through March 31, 2003.
\end{abstract}




\section{Investigation of Fischer-Tropsch Mechanisms Using Probe Molecules}

L. Hou, Y. Zhang, J.W. Tierney and I. Wender

Chemical Engineering Department, University of Pittsburgh

The Fischer Tropsch Synthesis (FTS) is a sustainable technology for super clean transportation fuels as well as chemicals from coal, natural gas, biomass and any carbonaceous resource. Understanding the reaction mechanism of the complex reactions taking place during the FTS is important for designing efficient FTS catalysts and processes. Incorporating probe molecules has proven to be an effective way of investigating the FTS mechanism. Terminal and internal alkynes have been used as probes in our previous investigations. It has been found that acetylenic compounds can effectively initiate the FTS and produce $\mathrm{Cn}+$ products even at lower temperatures $\left(150^{\circ} \mathrm{C}\right.$, which is about $70^{\circ} \mathrm{C}$ lower than normal FTS operating temperature. Incorporation of terminal alkynes produces straight chain hydrocarbons, and primary alcohols and aldehydes with one carbon more than the added acetylenic probe. Internal alkynes are less effectively incorporated and branched products are obtained.

Recently, acetylenic compounds, such as 4-phenyl-1-butyne and phenylacetylene have been used to probe the FTS mechanism on iron and cobalt catalysts. The phenyl group in these probes could be a marker for interpreting the mechanisms involved in the FTS and incorporation of alkyne probes.

$\mathrm{A} \mathrm{Co} / \mathrm{Al}_{2} \mathrm{O}_{3}$ catalyst was prepared by the incipient wetness impregnation technique with $10 \%$ wt cobalt loading on $\gamma-\mathrm{Al}_{2} \mathrm{O}_{3}$. The iron catalyst was obtained from Dr. Davis at the University of Kentucky; it had been prepared by a precipitation method and had a composition of $100 \mathrm{Fe}-5.1 \mathrm{Si}-2.0 \mathrm{Cu}-5.0 \mathrm{~K}_{2} \mathrm{O}$. Catalytic performance was evaluated in a tubular fixed bed reactor. Typically, 0.5 to 1 grams of catalyst were mixed with 1 gram of quartz and loaded into the reactor, and then activated by pure $\mathrm{H}_{2}$ at $350^{\circ} \mathrm{C}$ for 10 hours. Typical reaction conditions are: for cobalt catalysts, $100 \mathrm{psi}, 150-220^{\circ} \mathrm{C}, \mathrm{H}_{2} / \mathrm{CO}=2$; for iron catalysts, $100 \mathrm{psi}, 170-250{ }^{\circ} \mathrm{C}$, $\mathrm{H}_{2} / \mathrm{CO}=0.7$. Probe molecules, specifically phenylacetylene or 4-phenyl-1-butyne were added in n-pentane by a syringe pump. Acetylene concentration in the pentane was $10 \%$ and the flow rate of the solution was $2 \mathrm{ml} /$ hour.

Results show that both phenylacetylene and 4-phenyl-1-butyne can initiate the FT reaction on iron and cobalt catalysts at lower temperatures than those at which normal FT reactivity is negligible. It has been shown that the phenyl group on these probes is an excellent marker, since every product derived from such probes contains a phenyl group. At lower temperatures, only acetylenic compounds initiated the FTS; at higher temperatures, both normal FTS reactions and acetylenic compounds initiate FT reactions. These two types of reactions can be distinguished clearly by GC and GCMS. A typical GCMS analysis of products of the incorporation of phenyl-1-butyne is shown in Figure 1.

Incorporation of phenylacetylene into the FTS on iron catalysts leads to chain-growth from the acetylene chain on the phenyl group. In addition to hydrocarbons, oxygenates, such as phenylpropanal, phenylpropanol, phenylbutynal and phenylbutanol are also observed. Similar products are obtained on cobalt catalysts; however, oxygenates are not observed. Incorporation of 4-phenyl-1-butyne leads to chain-growth on the $\mathrm{C}_{4}$ chain. This probe resembles incorporation of 1-butyne except that the phenyl group is far from the carbon-carbon triple bond. Iron and cobalt catalysts show differences on formation of oxygenates. With cobalt catalysts, oxygenates 
observed were only one carbon more than the added alkyne, similar to a hydroformylation reaction. With iron catalysts, a spectrum of oxygenates with one, two, and three carbons more were obtained. It may be that formation of oxygenates on iron catalyst is by $\mathrm{CO}$ insertion into the growing intermediates, while formation of oxygenates on cobalt catalysts is by a hydroformylation-like reaction involving an adsorbed species with a preserved double bond. A postulation is that the complex FTS reactions involve two major types of intermediates: one is a growing substrate containing two or more carbons; another is a building block containing only one carbon. The chain growth in normal FTS is by adding methylene building blocks one-byone to the growing substrate. Adsorption of acetylenic compounds initiates the carbon chain in the FTS. Great enhancement of the FTS at lower temperatures indicates that formation of the growing substrate is the rate-determining-step.

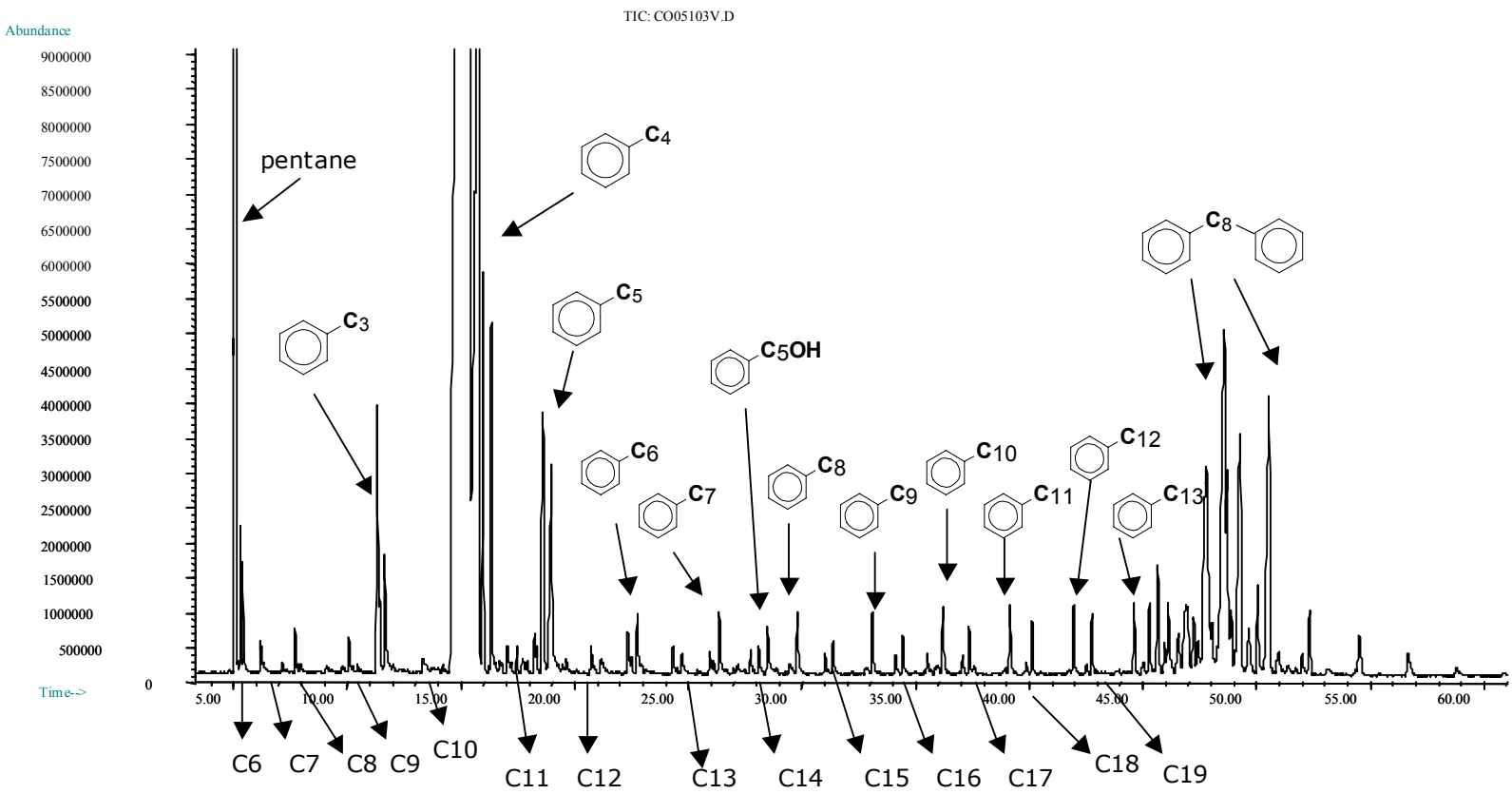

Figure $1 \mathrm{GC}-\mathrm{MS}$ of F-T product distribution on Co with 4-phenyl-1-butyne as a probe. $\mathrm{T}=220 \mathrm{oC}, \mathrm{P}=100 \mathrm{psi}, \mathrm{H}_{2} / \mathrm{CO}=2$, flow rate of phenylacetylene $(10 \%)$ in pentane is $2 \mathrm{ml} /$ hour. 


\section{Diesel and Jet Fuel from Fischer-Tropsch Wax \\ Z. Zhong, Y. Zhang, J. Tierney and I. Wender \\ Chemical Engineering Department, University of Pittsburgh}

There is an increasing demand for ultraclean, efficient transportation fuels. Diesel and jet fuels are of especial importance. The Fischer-Tropsch (F-T) process produces long-chain normal paraffins, which contain no sulfur, nitrogen, aromatics or heavy metals. A large part of the F-T product consists of waxes; these waxes can be a source of high quality diesel and jet fuels, as well as lube-base oils.

We have been investigating a novel type of catalyst for the conversion of these F-T waxes to desired product fractions. These catalysts consist of Pt-promoted anion-modified zirconia catalysts, $\mathrm{Pt}(0.5 \mathrm{wt} \%) / \mathrm{WO}_{3}(12.5 \mathrm{wt} \%) / \mathrm{ZrO}_{2}$, labeled (A), and $\mathrm{Pt}(0.5 \mathrm{wt} \%) / \mathrm{SO}_{4}(9$ $\mathrm{wt} \%) / \mathrm{ZrO}_{2}$, labeled $\mathrm{B}$, and various modifications and mixtures of these catalysts. It is known that (A) is a good isomerization catalyst while (B) is a good cracking catalyst. To achieve acceptable yields to middle range products such as diesel and jet fuel ranges, appropriate degrees of hydroisomerization and hydrocracking are required. We have focused on a study of the preparation of (A) and of (B), mixtures of (A) and (B) and on the addition of $\mathrm{H}_{2} \mathrm{SO}_{4}$ to (A). The hydrogen pressure in the reaction is of major importance, affecting (A) and (B) inversely. In earlier research, we investigated the feasibility of synthesizing a hybrid catalysts consisting of (A) and a mordenite component with an improved performance in converting long-chain paraffins into fuels. That result demonstrated a promising method of combining functions of different catalysts.

In a similar way, we synthesized hybrid catalysts with various components and ratios. However, under the reaction conditions we used in studying pure (I) or (II) (200 C, $500 \mathrm{psi}_{2}$ ), it was difficult to examine the functions of the components in the hybrid catalysts because (B) demonstrated much higher reactivity than (A). We found that hydrogen pressure plays a critical role in affecting the activities of the two catalysts in converting long-chain paraffins. With the decrease of hydrogen pressure from 500 psi to $100 \mathrm{psi}$, the conversion of $\mathrm{nC}_{36}$ over (A) increased from $40 \mathrm{wt} \%$ to $99 \mathrm{wt} \%$ (cat. $/ \mathrm{nC}_{36}=1: 4 \mathrm{wt}, 200 \mathrm{C}, 25 \mathrm{~min}$ ); over (B), the conversion of $\mathrm{nC}_{36}$ decreased from $93 \mathrm{wt} \%$ to $45 \%$ (cat. $/ \mathrm{nC}_{36}=1: 6 \mathrm{wt}, 200 \mathrm{C}, 20 \mathrm{~min}$ ). Minimum hydrogen pressures have to be maintained; initial hydrogen pressure below 100 psi resulted in decreased reactivity of (A). See Fig.1.

Pt-loading can also affect the behavior of the two catalysts. We synthesized catalysts with Pt-loadings from $0.05 \mathrm{wt} \%$ up to $5 \mathrm{wt} \%$. For a catalysts promoted with Pt containing more than 1 $\mathrm{wt} \%$, the increase of Pt does not apparently affect performance. The catalysts turned to a dark color after calcination at $700 \mathrm{C}$, showing that larger Pt particles are formed by agglomeration. Many factors are involved in the interactions between Pt and the SZr or WZr supports. Fixing reaction conditions at $100 \mathrm{psi}$ and $200 \mathrm{C}$, hybrid catalysts synthesized by thoroughly grinding zirconia catalysts modified by sulfate and tungstate followed by calcination at $650 \mathrm{C}$ for 3 hours were tested. Improved yields of diesel fuel products have been observed with hybrid catalysts with PtWZr and SZr components. See Fig.2.

Conversion of a Sasol H1 wax has been studied using simulated distillation. A high percentage of diesel fuels were obtained after the wax was treated with (A) and (B) catalysts. 


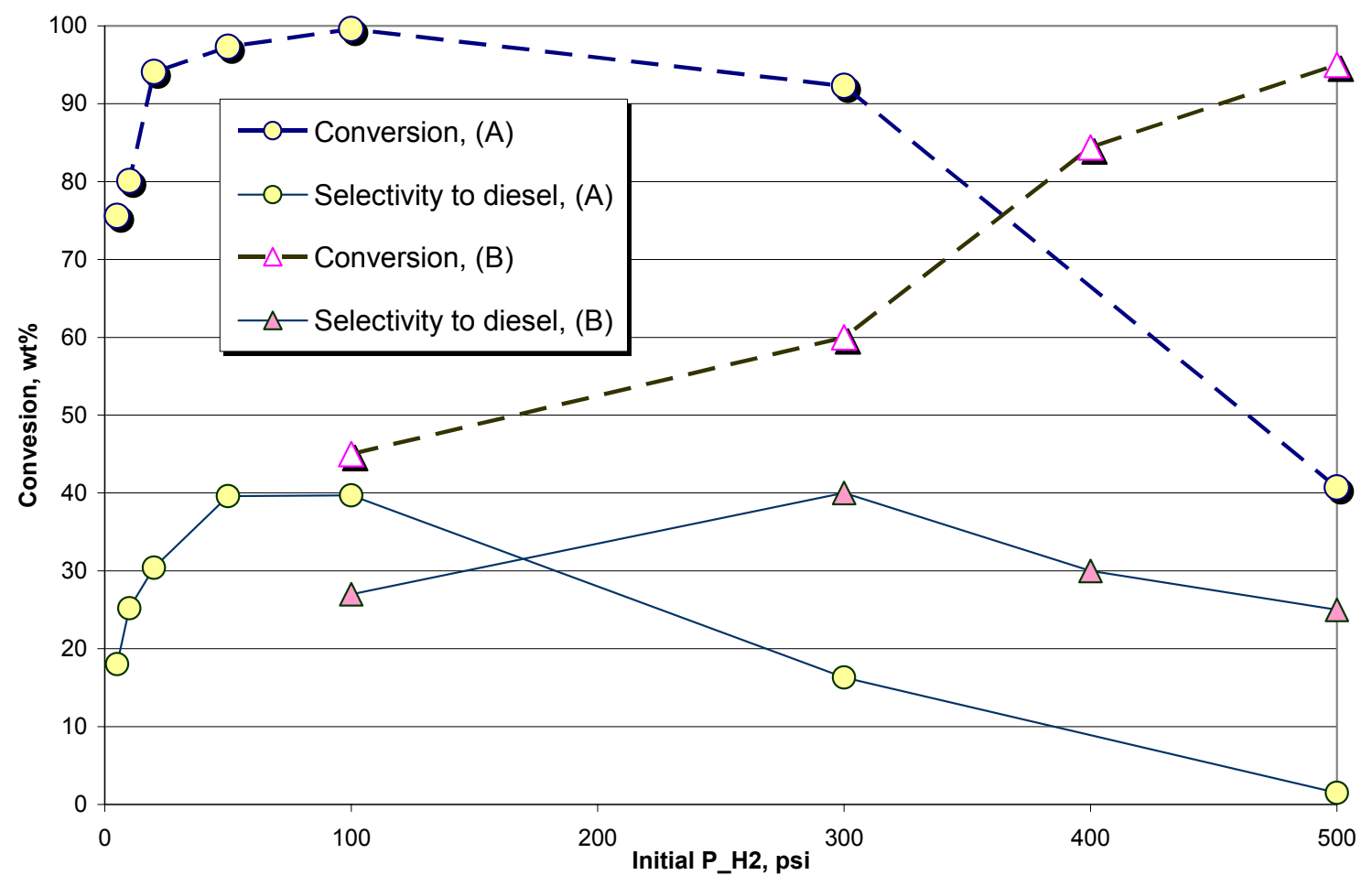

Fig.1. Effects of hydrogen pressure on conversion of $\mathrm{nC} 36$ over catalyst (A) and (B) Cat./ $\mathrm{nC}_{36}=1: 4 \mathrm{wt}, 200 \mathrm{C}, 25 \mathrm{~min}$ for (A), $20 \mathrm{~min}$ for (B)

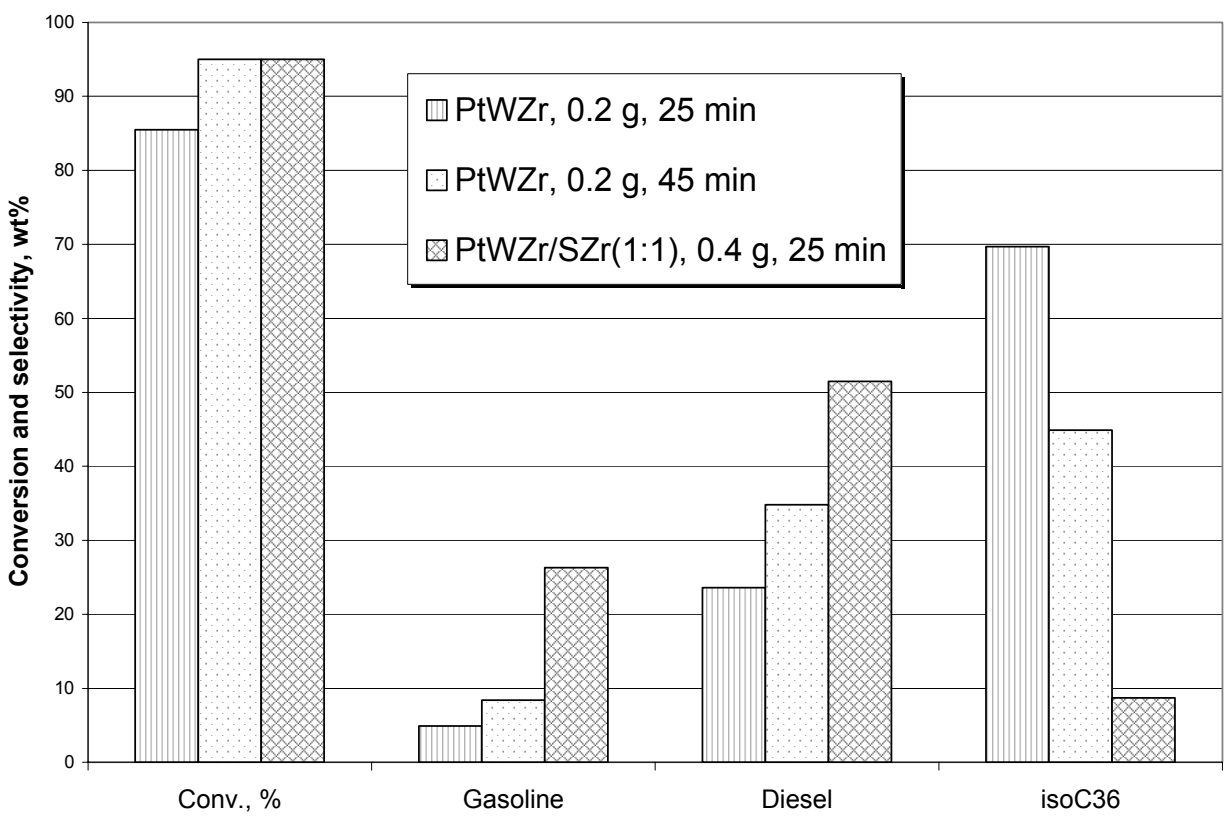

Fig.2. Hybrid catalyst has higher activity and selectivity to diesel fuel. SZr by itself has no activity under the same reaction conditions. Reactant $\left(\mathrm{nC}_{36}\right)=0.8 \mathrm{~g}, 200 \mathrm{C}$, initial hydrogen pressure $=100$ psi. 


\section{Sol-Gel Catalyst F-T Synthesis of Diesel Fuel \\ Brian C. Dunn, Paul Cole, Dan Covington, and Edward M. Eyring \\ University of Utah}

Significant progress has been achieved over the past six months in the development of sol-gel based silica supports for Fischer-Tropsch (F-T) catalysts. These catalysts afford a much greater level of control over the support properties than traditionally prepared catalysts do. The density, pore size, and pore volume of the support can be varied in a continuous fashion from a very dense $\left(2.2 \mathrm{~g} \mathrm{~cm}^{-3}\right)$, microporous xerogel to a non-dense $\left(0.08 \mathrm{~g} \mathrm{~cm}^{-3}\right)$, and mesoporous aerogel by proper manipulation of chemistry and processing conditions. The amount of active metal catalyst is also easily controlled based upon the quantity of metal precursor added to the silica, either pre- or post-gelation.

The catalysts are prepared with either tetramethoxysilane (TMOS) or tetraethoxysilane (TEOS) which react with water in the presence of an acid or base catalyst. As the silane reacts to form the -Si-O-Si- structure, the particles of silica grow and cross-link until the solution changes from a sol (dispersion of liquid silane in alcohol / water mixture) into a gel (solid, threedimensional structure). The pores of the gel are filled with a mixture of alcohol and water at this stage of processing. For the preparation of xerogels, an acid gelation catalyst is employed and metal salts $\left(\mathrm{Co}\left(\mathrm{NO}_{3}\right)_{2}\right.$ or $\left.\mathrm{Fe}\left(\mathrm{NO}_{3}\right)_{2}\right)$ are incorporated into the sol, and the salts remain in the pore-filling solution during and after gelation. The solution is slowly evaporated from the pores and the differential surface tension from the evaporating solvent causes the pores of the gel to collapse resulting in dense xerogels. Aerogels are prepared by first preparing the solid gel using a base gelation catalyst. The metal salts are added only after gelation because the base catalyst causes precipitation of metal hydroxides. The salts are incorporated by soaking the gel in an alcohol solution of the metal salt and the aerogels are formed when the solvent is removed as a supercritical fluid from the pores of the gel without causing pore collapse. The supercritical solvent does not transition from the liquid phase into the gas phase as in the xerogel case.

Our early experiments focused on replacing the pore-filling alcohol solution of metal salt with liquid $\mathrm{CO}_{2}$, then transitioning the $\mathrm{CO}_{2}$ into the supercritical state by raising the temperature. $\mathrm{CO}_{2}$ was used because of the ease of exceeding both the critical pressure (1071 psi) and critical temperature $\left(31.1{ }^{\circ} \mathrm{C}\right)$. However, the metal containing gels collapsed to form xerogels rather than aerogels. Recently, we have prepared metal loaded aerogels by removing the pore-filling solvent by transitioning the alcohol into the supercritical phase. The gel containing a metal salt is placed in an autoclave filled with alcohol. The autoclave is sealed and slowly heated above the critical temperature $\left(243.1{ }^{\circ} \mathrm{C}\right.$ for ethanol) and since the autoclave is sealed, the internal pressure rises above the critical pressure (926 psi). The supercritical alcohol is slowly released from the autoclave while maintaining the temperature above the critical point so that when the pressure drops below the critical pressure, the alcohol transitions into the gas phase, thereby avoiding the gas-liquid interface which would cause pore collapse. During this process, the metal nitrate is transformed into the corresponding metal oxide which can be reduced to the metal in a stream of hydrogen. Experiments to test these aerogel materials as F-T catalysts are underway. The aerogels will be loaded with iron rather than cobalt since experiments with cobalt-based catalysts are being phased out in our laboratory.

Many reports have appeared over the last year dealing with synthesis and characterization of aerogel materials with metal or metal oxide dopants. Iron and iron oxide containing aerogels ${ }^{1-}$

${ }^{4}$ have been created and characterized, nickel and nickel oxide ${ }^{5}$ aerogels have been prepared and 
characterized, $\mathrm{Pd}, \mathrm{Ru}, \mathrm{Rh}, \mathrm{Ag}$, and $\mathrm{Cu}$-containing aerogels have been synthesized, ${ }^{6-7}$ and an alloy of cobalt and iron ${ }^{8-10}$ has been observed in an aerogel. However, none of these studies reports on catalytic activity. Our laboratory has unusual capabilities for both synthesizing the sol-gel based materials and evaluating them for catalytic performance.

The laboratory-scale reactor (built by Ron Pugmire) has been modified for F-T synthesis and has been equipped with an online GC/MS system for identification and quantitation of the FT products. The interface between the F-T reactor and GC/MS is a valve-less ambient vapor sampler (AVS) developed by the Meuzelaar group at Utah. As the AVS has no valves, it achieves zero-volume holdup between samples and has little possibility of cross contamination. The first experiments using the GC/MS system focused on evaluating the influence of cobalt metal loading of xerogel catalysts on the F-T synthesis.

A series of xerogel catalysts containing metallic cobalt were prepared ranging from a mole ratio $\left(\mathrm{Co} / \mathrm{SiO}_{2}\right)$ of 0.05 to 0.20 . The varying loading of the catalyst may result in differing sizes of the metal particles in the silica support ${ }^{11}$. All of the catalysts have been evaluated in our laboratory-scale F-T reactor and a subset has been characterized by XRD by Prof. Seehra at West Virginia University. XRD indicates the presence of $\mathrm{CoO}$ as the only form of cobalt in the 0.05 sample while the 0.10 and 0.15 samples show both $\mathrm{CoO}$ and metallic cobalt (particle size about 7 $\mathrm{nm})$. Presumably, the oxide forms after $\mathrm{H}_{2}$ reduction of the $\mathrm{Co}\left(\mathrm{NO}_{3}\right)_{2}$ xerogel when the sample is exposed to the atmosphere. Additional reduction of the oxide may occur when the catalyst is loaded into the F-T reactor and subjected to the 2:1 mixture of $\mathrm{H}_{2}$ and $\mathrm{CO}$ used as reactants for the F-T synthesis. The series of Co xerogel catalysts show a general trend of increasing product yield and increasing molecular weight of the F-T products at $300{ }^{\circ} \mathrm{C}$ as the loading of Co increases. The largest hydrocarbon produced with the 0.05 catalyst is $<\mathrm{C}_{8}, \mathrm{C}_{12}$ with $0.10, \mathrm{C}_{15}$ with 0.15 , and $\mathrm{C}_{20}$ with 0.20 .

\section{References}

1. L. Casas, A. Roig, E. Molins, J. M. Greneche, J. Asenjo, J. Tejada, "Iron oxide nanoparticles hosted in silica aerogels," Appl. Phys. A, 2002, 74, 591-597.

2. P. Fabrizioli, T. Burgi, M. Burgener, S. van Doorslaer, A. Baiker, "Synthesis, structural and chemical properties of iron oxide-silica aerogels," J. Mater. Chem., 2002, 12, 619-630.

3. P. Fabrizioli, T. Burgi, A. Baiker, "Environmental catalysis on iron oxide-silica aerogels: selective oxidation of $\mathrm{NH}_{3}$ and reduction of $\mathrm{NO}$ by $\mathrm{NH}_{3}$," Journal of Catalysis, 2002, 206, 143-154.

4. C. Cannas, M. F. Casula, G. Concas, A. Corrias, D. Gatteschi, A. Falqui, A. Musinu, C. Sangregorio, G. Spano, "Magnetic properties of $-\mathrm{Fe}_{2} \mathrm{O}_{3}-\mathrm{SiO}_{2}$ aerogel and xerogel nanocomposite materials," J. Mater. Chem., 2001, 11, 3180-3187.

5. M. F. Casula, A. Corrias, G. Paschina, "Nickel oxide-silica and nickel-silica aerogel and xerogel nanocomposite materials," J. Mater. Res., 2000, 15, 2187-2194.

6. B. Heinrichs, S. Lambert, C. Alie, J. P. Pirard, G. Beketov, V. Nehasil, N. Kruse, "Cogelation: an effective sol-gel method to produce sinter-proof finely dispersed metal catalysts supported on highly porous oxides," Studies in Surface Science and Catalysis, 2002, 143, 25-33.

7. P. Moggi, S. Morselli, G. Predieri, "Sol-gel routes for the preparation of heterogeneous catalysts based on Ru, Rh, Pd supported metals," Studies in Surface Science and Catalysis, 2002, 143, 669-677. 
8. M. F. Casula, A. Corrias, G. Paschina, "Iron-cobalt-silica aerogel nanocomposite materials," J. Sol-Gel Sci. Tech., 2003, 26, 667-670.

9. M. F. Casula, A. Corrias, G. Navarra, "An EXAFS study on iron-cobalt-silica nanocomposite materials prepared by the sol-gel method," J. Sol-Gel Sci. Tech., 2003, 26, 453-456.

10. M. F. Casula, A. Corrias, G. Paschina, "FeCo- $\mathrm{SiO}_{2}$ nanocomposite aerogels by high temperature supercritical drying," J. Mater. Chem., 2002, 12, 1505-1510.

11. G. Jacobs, T. K. Das, Y. Zhang, J. Li, G. Racoillet, B. H. Davis, "Fischer-Tropsch synthesis: support, loading, and promoter effects on the reducibility of cobalt catalysts," Appl. Catalysis A: General, 2002, 233, 263-281.

Publications

1. B. C. Dunn, P. Cole, D. J. Covington, E. C. Heider, J. Gasser, E. M. Eyring, H. L. C. Meuzelaar, and R. J. Pugmire "Fischer-Tropsch catalysts supported on sol-gel derived silica", Fuel Chemistry Division Preprints, 2003, in press.

2. N. S. Roh, B. C. Dunn, E. M. Eyring "Production of diethyl carbonate from ethanol and carbon monoxide over a heterogeneous catalyst in a flow reactor" Fuel Processing Technology, 2003, in press.

\section{$\underline{\text { Presentations }}$}

1. B. C. Dunn, P. Cole, D. J. Covington, E. C. Heider, J. Gasser, E. M. Eyring, H. L. C. Meuzelaar, and R. J. Pugmire "Fischer-Tropsch catalysts supported on sol-gel derived silica", 225 $5^{\text {th }}$ ACS National Meeting, New Orleans, LA, March 2003.

2. B. C. Dunn, P. Cole, D. J. Covington, E. C. Heider, J. Gasser, E. M. Eyring, H. L. C. Meuzelaar, and R. J. Pugmire "Preparation of amorphous silica supports for Fischer-Tropsch catalysts by sol-gel chemistry", Gordon Research Conference on Hydrocarbon Resources, Ventura, CA, January 2003. 


\section{Organometallic precursors for F-T catalysts}

Richard D. Ernst, University of Utah

A part of our effort is being directed to the use of metal pentadienyl compounds as deposition agents for iron and ruthenium on surfaces appropriate for Fischer-Tropsch catalysis. Our first attempts will utilize bis(2,4-dimethylpentadienyl) complexes, i.e., $1(\mathrm{M}=\mathrm{Fe}, \mathrm{Ru})$ and

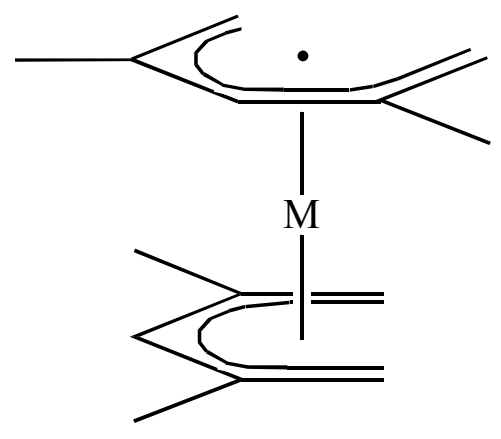

1

aerogels currently in use in the Eyring group. We have already shown that a variety of such compounds serve as ideal sources for metal film depositions, ${ }^{1}$ by a process in which the pentadienyl ligands couple together and are released from the metal as a neutral decatetraene molecule. There also would be a possibility for surface attachment via protonation of the formally anionic dienyl ligands, as we have demonstrated for chromium analogues ${ }^{2}$. For at least ruthenium, but perhaps iron as well, a variation of this approach is also possible via direct protonation of the starting complexes, which converts one of the formally anionic dienyl ligands into a neutral diene (see 2), which is then susceptible to replacement by added ligands, ${ }^{3}$ perhaps even surface oxygen sites.
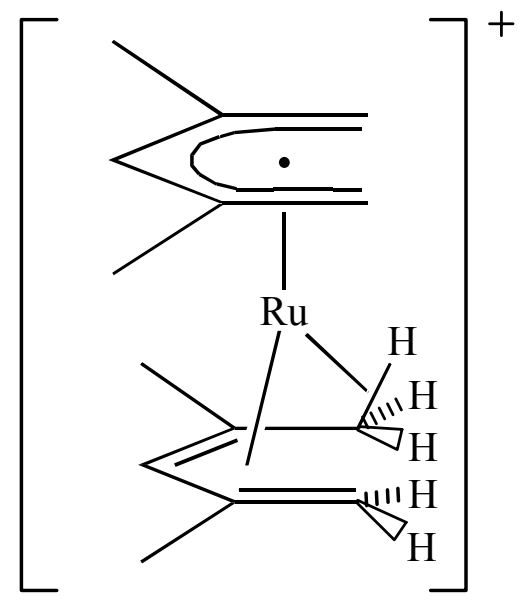

2

Other studies we have carried out have demonstrated that cyclic polyene and polyenyl ligands are much more prone to undergoing hydrogen atom transfer reactions, whether as acceptors or donors, than had previously been recognized. ${ }^{4}$ Such processes are responsible for catalytic hydrogenations of arenes, giving rise to intermediates such as 3 , which are in fact 


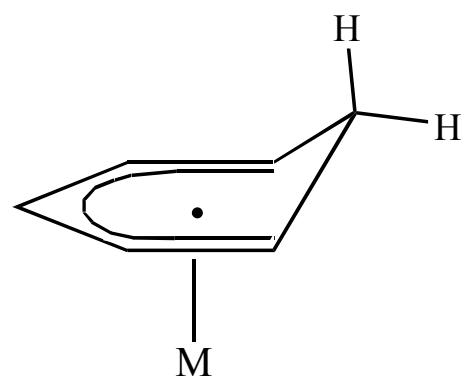

3

dienyl complexes quite similar to many complexes we study. Hence, these complexes should be ideal catalysts for this process, and perhaps also for the reverse process, catalytic dehydrogenations of cycloalkenes.

\section{$\underline{\text { References }}$}

1. Spencer, J.T.; Ernst, R.D. U.S. Patent 5,352,488 (Oct. 4, 1994).

2. Freeman, J.W.; Wilson, D.R.; Ernst, R.D.; Smith, P.D.; Klendworth, D.D., McDaniel, M.P. J. Polym. Sci. 1987, 25A, 2063.

3. Newbound, T.D.; Stahl, L.; Ziegler, M.L.; Ernst, R.D. Organometallics 1990, 9, 2962.

4. Basta, R.; Arif, A.M.; Ernst, R.D. Organometallics 2003, 22, 812. 


\section{Silicon-29 NMR studies of xerogel supported F-T catalysts}

Ron Pugmire group, University of Utah

Silicon-29 NMR studies were recently initiated on the aerogel samples that are prepared in the Eyring research group. As mentioned in the Eyring report "significant progress has been achieved over the previous six months in the development of sol-gel based silica supports for Fischer-Tropsch (F-T) catalysis." Preliminary studies are included in this report from three aerogel samples from the Eyring lab: 1) an aerogel prepared from tetraethoxysilane in water in the presence of an acid catalyst; 2) an aerogel in which $\mathrm{Co}\left(\mathrm{NO}_{3}\right)_{2}$ has been incorporated into the gel but the sample has not been calcined; 3) same as 2) but the sample has been calcined as described in the report of the Eyring group.

The preliminary data on samples 1-3 are given in the attached figure and the spectra are labeled $\mathrm{a}, \mathrm{b}$, and $\mathrm{c}$, respectively. The ${ }^{29} \mathrm{Si}$ solid state NMR spectrum for a silicate material can yield quantitative information in the form of the degree of Si atom coordination around bonded $\mathrm{Si}\left(\mathrm{O}_{1 / 2}\right)_{4}$ tetrahedral units. These tetrahedral sub-units are designated $\mathrm{Q}_{\mathrm{n}}$. There are five possible states (designated $\mathrm{Q}_{0}, \mathrm{Q}_{1}, \mathrm{Q}_{2}, \mathrm{Q}_{3}, \mathrm{Q}_{4}$ ) that can be present in the NMR spectrum. Typical chemical shift values with characteristic values in the $\mathrm{Q}$ region are: $\mathrm{Q}_{\mathrm{o}}=-72$ to $-82 \mathrm{ppm} ; \mathrm{Q}_{1}=$ 82 to -89 ppm; $\mathrm{Q}_{2}=-92$ to $-96 \mathrm{ppm} ; \mathrm{Q}_{3}=-100$ to $-104 \mathrm{ppm} ;$ and $\mathrm{Q}_{4}=\sim-110^{1-5}$ where $\mathrm{Q}_{\mathrm{o}}$ is designated a single tetrahedron, $\mathrm{Q}_{1}$ an end group, $\mathrm{Q}_{2}$ a middle group, $\mathrm{Q}_{3}$ a branching site, and $\mathrm{Q}_{4}$ a cross-linking group.

The spectrum of the aerogel sample (figure a) exhibits 3 peaks at $-92,-101$, and -110 with relative intensities of 6,33 , and $61 \%$, respectively. Hence the spectrum is dominated by $\mathrm{Q}_{3}$ and $\mathrm{Q}_{4}$ tetrahedral units (branching and cross-linking) with a minor amount $(\sim 6 \%)$ of middle group. Addition of the cobalt salt (without calcinations) produced the spectrum in figure $b$ but the distinct spectral lines have now disappeared. A similar spectrum is noted in figure $\mathrm{c}$ where the cobalt loaded aerogel has been calcined.

In spectrum a the relative amounts of $\mathrm{Q}_{3}$ and $\mathrm{Q}_{4}$ units suggests that a well defined structure exists in the aerogel. The spectra in $b$ and $c$ do not clearly delineate the structural subunits observed in spectrum a. However, the chemical shift regimes are still present indicating that depolymerization has probably not occurred. The effects of calcining will be explored without the addition of cobalt in order to separate the effects of heating on the basic aerogel structure. Significant variations in the ${ }^{29} \mathrm{Si}$ spin lattice times are observed in the three samples studied to date.

\section{References}

1. S. K. Young, W. L. Jarrett, and K. A. Mauritz, Pol. Eng. Science, 2001, 41, 1529.

2. Lipmaa, et. al., J. Am. Chem. Soc. 1980, 102, 4889.

3. F. Babonneau, K. Thorne, and J. D. Mackenzie, Chem. Mater. 1989, 1, 554.

4. T. M. Alum, R. A. Assink, and D. A. Loy, Chem. Mater. 1996, 8, 2366.

5. M. P. J. Peeters, W. J. J. Wakelkamp, and A. P. M. Dentgens, J. Non-Cryst. Solids, 1995, $189,77$. 


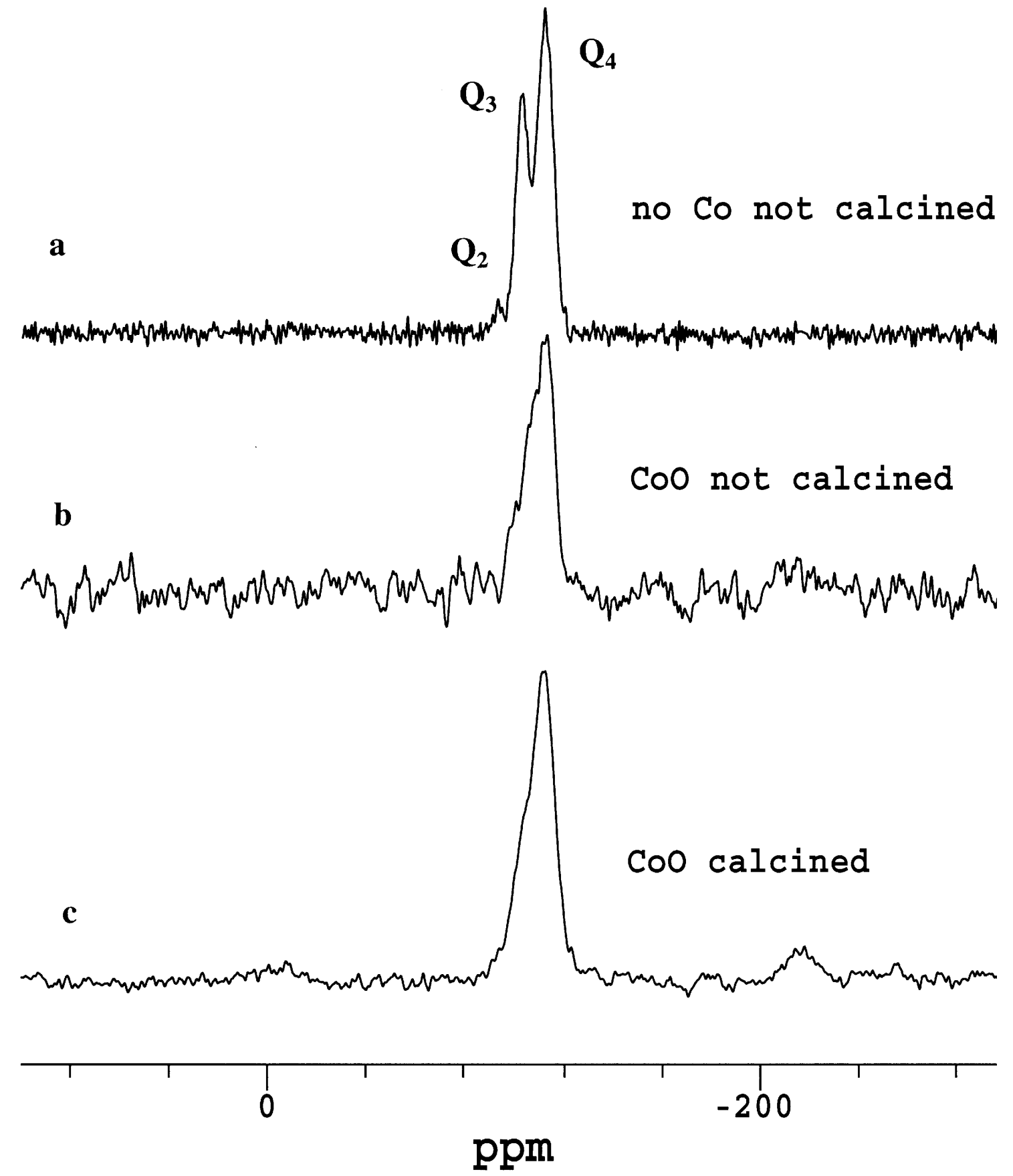




\section{On-line GC/MS Analysis of Fischer Tropsch Reaction Products; Investigation and Evaluation of Metal Carbonyl Formation Processes \\ Henk Meuzelaar*, Neil Arnold* and Paul Cole** \\ * Center for Microanalysis and Reaction Chemistry, Department of Chemical and Fuels \\ Engineering \\ ** Department of Chemistry. \\ University of Utah}

\section{Introduction}

Over the past six months much of our on-line GC/MS analysis efforts has focused on the interpretation and evaluation of unexpectedly strong iron pentacarbonyl signals observed during the initial Fischer Tropsch reactor start-up experiments (see figure 1).

The formation of metal carbonyls is a well known phenomenon among FT process chemists and engineers. In fact, transient metal carbonyl complexes are thought to play a key role in the hydrocarbon synthesis mechanism itself [Je, 1995; Purwanto, 2000; Wender, 1962]. For instance, whereas cobalt carbonyl complexes are thought to promote the formation of longer chain hydrocarbons, nickel carbonyl has been reported to promote the formation of methane instead [Zubrin, 1997]. What is, however, less well known are the potential effects of high concentrations of carbonyl compounds in the gas phase. The mobility of catalytic atoms via the creation, and eventual disassociation, of gas phase carbonyl compounds has a variety of implications for catalyst lifetimes, reaction mechanisms, and the product transport within the bed.

So, from the perspective of process development as well as catalyst testing it is important to know which metal carbonyl complexes are dominant in the reactor at any given stage in the process. Besides potentially altering the rate and selectivity of the catalytic process, the presence of unwanted metal carbonyls may lead to deactivation of the catalyst being tested [Air Products and Chemicals, Inc. and Eastman Chemical Company, 1998; Davis, 1998; Klier, 1999]. Moreover, in view of the thermal lability of many metal carbonyl compounds and their tendency to dissociate on reactor, catalysts and transfer line surfaces [Klier, 1999; Purwanto, 2000] the observation of iron pentacarbonyl only does not rule out the transient formation and deposition of other metal carbonyl compounds capable of influencing Fischer Tropsch process reactions. Last but not least, metal carbonyl compounds are notoriously volatile and toxic [EPA Chemical Profile, 1987], thus requiring appropriate care in handling, e.g. when opening the reactor.

Consequently, one cannot simply ignore these phenomena. Instead, it would seem to behoove all FT process developers and users to carefully monitor the reactor processes for the presence of unwanted metal carbonyl compounds, lest the FT process results might be misinterpreted, on-line process sensors and other analytical devices damaged and/or unexpected health risks created. 


\section{Experimental Findings}

With the invaluable help of the Eyring group the authors of this report set out to throw light on the precise origin and fate of the observed $\mathrm{Fe}(\mathrm{CO})_{5}$ vapors as well as to examine the effectiveness of various procedures described in the literature and designed to minimize metal carbonyl formation outside the designated catalyst bed.

Figure 1 illustrates the initial result which inspired subsequent investigation. This figure shows a chromatogram from an initial startup experiment involving the deposition of a cobaltloaded silica xerogel catalyst. This figure illustrates a sequence of peaks most of which are aliphatic and olefinic reaction products. The range of compounds analyzed was from C5 to C19. The surprise is located in the first peak in the chromatogram which represents approximately as much material as all of the other peaks combined!

Figure 2 shows the mass spectrum of the primary constituent of this first peak. This spectrum as been identified as iron pentacarbonyl and the GC retention time is consistent with this identification. This identification was a great surprise given that the reactor was being operated with a cobalt catalyst! It has been subsequently confirmed by several means.

This initial experiment was performed using a $0.86 \mathrm{~g}$. $(\sim 1 \mathrm{ml})$ charge of a silica xerogel catalyst loaded with 0.3 mol. cobalt per $1.0 \mathrm{~mol}$. silicon, which was placed in a stainless steel (SS) tube 6" X 0.180" i.d. fitted with a 20 um SS frit and a 2" X 0.020" SS sheath thermocouple. The charge is held in place by two QMA-type quartz fiber filters in front of and behind the catalyst (4 total). The reaction chamber was operated at $225 \mathrm{C}$ with $135 \mathrm{sccm} \mathrm{He}, 90 \mathrm{sccm} \mathrm{H}_{2}$, and $45 \mathrm{sccm}$ CO.

The on-line GC/MS system was interfaced to the effluent of the back pressure regulator on the reaction chamber. Samples were taken at approx. 15 minute intervals using the AVSTLGC/MS instrument previously described [Jakab, 1996]. Effluent samples were taken for 1 second at ambient pressure $(\sim 650 \mathrm{~mm} \mathrm{Hg})$ and separated on a $1 \mathrm{~m}$ x 100 um i.d. column with .1 um 5\% phenyl methyl silicone stationary phase (Altech AT-5). The MS module was scanned from $\mathrm{m} / \mathrm{z} 50$ to 350 at 3 scans per second.

As already indicated, the presence of iron was completely unexpected, but the GC/MS result was unambiguous. It was suspected that the material was originating from the apparatus, in particular the stainless steel (SS) components operating at either high pressure or high temperature.

The carbon monoxide tank was tested and no $\mathrm{Fe}(\mathrm{CO})_{5}$ was detected. The ss tube and ss frit were replaced by a Silcosteel tube and a Pyrex frit. This change did not reduce the production of $\mathrm{Fe}(\mathrm{CO})_{5}$.

When the Silcosteel/Pyrex reaction chamber was operated with only $\mathrm{He} / \mathrm{CO}$ at $25{ }^{\circ} \mathrm{C}$ (with catalyst) with the downstream manifold at $200^{\circ} \mathrm{C}$ (it's normal temp.) there appeared to be a small amount of $\mathrm{Fe}(\mathrm{CO})_{5}$. The amount was on the order of 100 times less. But the peak was very small. Only 4 of the 6 representative ions were present and the signal to noise ratio was about $2: 1$. This suggests that the $\mathrm{Fe}(\mathrm{CO})_{5}$ originated from the catalyst which was prepared using $\mathrm{Fe}\left(\mathrm{NO}_{3}\right)_{3}$ though it is reported to contain only $0.001 \% \mathrm{Fe}$. This does not seem like much, but the surface area of the catalyst is about $10^{6}$ times larger than the exposed stainless steel!

Subsequently, the presence of Fe has been further confirmed in the catalyst and reinforced by the formation of a rust-colored tint in waxes and hydrocarbon liquids collected from the reactor after exposure to air. Cobalt carbonyl or other metal carbonyl compounds have not been detected in the reactor effluent, but they are more thermally labile than the corresponding iron carbonyl compounds and more likely to decompose within the reactor. 
Methodological changes may be necessary to detect them, though their presence in the reactor seems likely.

A commercial silica drying gel was loaded in the chamber and operated in various conditions including $\left(25^{\circ} \mathrm{C}\right),\left(300^{\circ} \mathrm{C}\right),(\mathrm{He}),(\mathrm{He} / \mathrm{CO}),\left(\mathrm{He} / \mathrm{H}_{2}\right),\left(\mathrm{He} / \mathrm{H}_{2} / \mathrm{CO}\right)$. When the silica was removed it contained a dark magnetic material. This material was concentrated on the upstream side of the bed, where cooling from the incoming gas mixture may have facilitated deposition. A sample of this has been sent for analysis but results have not yet been returned. $\mathrm{Fe}(\mathrm{CO})_{5}$ was not detected in the effluent.

Additional experiments examined the effect of cobalt loading, reaction temperature and reaction gas composition on the amount of $\mathrm{Fe}(\mathrm{CO})_{5}$ produced. Changing the chamber temperature from $225^{\circ} \mathrm{C}$ to $255^{\circ} \mathrm{C}$ increased the hydrocarbon production but also doubled the $\mathrm{Fe}(\mathrm{CO})_{5}$, while at $275^{\circ} \mathrm{C}$ the $\mathrm{Fe}(\mathrm{CO})_{5}$ was reduced by a factor of 20 and at $300^{\circ} \mathrm{C}$ there was no $\mathrm{Fe}(\mathrm{CO})_{5}$ detected by $\mathrm{GC} / \mathrm{MS}$.

A $0.20 \mathrm{~mol}$ Co xerogel experiment showed production of $\mathrm{Fe}(\mathrm{CO})_{5}$ at $100^{\circ} \mathrm{C}$ but no hydrocarbons were produced. It started producing hydrocarbons at $175^{\circ} \mathrm{C}$. A series of cobalt loadings $(0.10,0.15,0.20$ and $0.25 \mathrm{~mol})$ was run at $300^{\circ} \mathrm{C}$. This high temperature was selected to eliminate the $\mathrm{Fe}(\mathrm{CO})_{5}$ signal, presumably due to immediate decomposition upon formation. The 0.20 Co catalyst had significant coking, the 0.25 Co coked so quickly that the pressure drop exceeded what the mass flow controller could supply.

All of these experiments have included monitoring for C8 through C24 hydrocarbons. The temperature, support, catalyst and reaction gas affect both the molecular weight distribution and the degree of unsaturation in the products. Typically, the higher the molecular weight the more saturated the products. In figure 1, for example, the transition from unsaturated to saturated occurs at about $\mathrm{C} 12$, with compounds below $\mathrm{C} 9$ being predominantly olefinic and compounds above $\mathrm{C} 15$ predominantly aliphatic. Evidence for trace levels of oxygenated species - aliphatic alcohols, aldehydes or ketones - are also present at the higher molecular weights.

\section{Conclusions and Recommendations}

During initial testing of the ss flow-through reactor reactor and silica-supported cobalt catalyst at $225^{\circ} \mathrm{C}$ in a $2: 1(\mathrm{v} / \mathrm{v}) \mathrm{H}_{2} / \mathrm{CO}$ mixture in helium relatively large quantities of $\mathrm{Fe}(\mathrm{CO})_{5}$ were observed in the reactor effluent. Whereas neither the $\mathrm{CO}$ cylinder, nor the ss transfer line, $\mathrm{SS}$ frit and SS reaction chamber walls appeared to be significant $\mathrm{Fe}(\mathrm{CO})_{5}$ sources, the xerogelsupported cobalt catalyst (at $0.2 \mathrm{w} / \mathrm{w}$ Co loading) appeared to be responsible for most of the observed $\mathrm{Fe}(\mathrm{CO})_{5}$ byproduct at reactor temperatures between 175 and $275^{\circ} \mathrm{C}$, apparently due to trace quantities of $\mathrm{Fe}$ in the catalyst. Although the $\mathrm{Fe}(\mathrm{CO})_{5}$ byproduct disappeared at $300 \mathrm{C}$, as expected on the base of its reported thermal stability, rapid coking was observed at this temperature of 0.2 and higher cobalt catalyst loadings.

In order to avoid potentially significant effects on the selectivity and activity of the cobalt and other catalysts to be tested it is recommended that a very high purity catalyst grade be employed and that on-line GC/MS process monitoring for $\mathrm{Fe}(\mathrm{CO})_{5}$ and potential other metal carbonyls be continued to avoid misinterpretation of Fischer Tropsch process mechanisms and kinetics. Moreover, in view of the known toxicity of $\mathrm{Fe}(\mathrm{CO})_{5}$ and other metal carbonyls it is strongly recommended that reactor effluents and contents be handled with the appropriate care. Finally, since $\mathrm{Fe}(\mathrm{CO})_{5}$ - plus potential other metal carbonyl products thus far escaping detection - tend to deposit readily on contacted surface it is recommended that transfer lines and analytical 
equipment downstream of the catalysts bed be regularly inspected and analyzed for the presence of metal deposits.

Metal carbonyl vapor deposition may well offer a practical direct route to the preparation of $\mathrm{Fe}, \mathrm{Co}, \mathrm{Cu}, \mathrm{Ni}, \mathrm{Ru}$ and other catalysts on fragile aerogel supports. Furthermore, the possibility of homogeneous catalysis in FT synthesis through the use of a support-less metal carbonyl (or other volatile metal compound) vapor reactor with near-zero transport limitations discussed by Wender et al. as early as 1962! - warrants further study. Conceptually, design and construction of a continuously regenerating vapor generation/deposition reactor with a high concentration metal carbonyl reaction zone for support-less, homogeneous catalysis studies would appear feasible.

\section{Literature Cited}

1. Air Products and Chemicals, Inc. and Eastman Chemical Company "Alternative Fuels Field Test Unit Support to Kingsport LPMEOHTM Demonstration Unit, December 1997 - January 1998," Topical Report to the U.S. Department of Energy under Cooperative Agreement No. DE-FC22-92PC90543, 1998.

2. Davis, B.H.; "Technology Development for Iron Fischer-Tropsch Catalysis," Final Report to U.S. Department of Energy on Contract DE-AC22-94PC94055, 1998.

3. “Chemical Identity - Iron, Pentacarbonyl," EPA Chemical Profile, CAS Registry Number: 13463-40-6, 1987.

4. Jakab, E.; Huai, H.; Nie, X.; Meuzelaar, H.L.C. "On-line GC/MS Techniques for Monitoring High Pressure Conversion Reactions," Process Control \& Quality, 1996, 8, 55-67.

5. Je, Y.T. and Companion, A.L. "A Theoretical Investigation of the CO Adsorption on Cobalt Surfaces: Co (00001), (1010), (1120), and (1012),” Bull. Korean Chem. Soc., 16, 729-736, 1995.

6. Klier, K.; Herman, R.G.; Beretta, A.; Burcham, M.A.; Sun, Q.; Cai, Y.; and Roy, B. "Zettlemoyer Center for Surface Studies, II. Cs/Cu/ZnO/CrzO and $\mathrm{Cs} / \mathrm{ZnO} / \mathrm{CrzO} \sim$ Catalysts as Single Beds and in a Double-Bed Configuration for Higher Alcohol Synthesis" Final Report to U.S. Department of Energy under Contract DE-FG22-95PC93052, 1999.

7. Purwanto, W.W. and Muharam, Y. "The Role of Catalysis for Effective Conversion and Utilization of Natural Gas Status and Perspective," Proc. Of the $6^{\text {th }}$ AEESEAP Triennial Conf., Kuta, Bali, Indonesia, Aug. 23-25, 2000.

8. Wender, I.; Sternberg. H.W.; Friedel, R.A.; Metline, S.J.; Markby, R.A.; "The Chemistry and Catalytic Properties of Cobalt and Iron Carbonyls," Washington, U.S. Govt. Print. Off., TN23.U4 no. $600622.06173,1962$.

9. Zubrin, R.; Kito, T.; and Frankie, B. "Construction and Operation of a Mars Methanol in situ Propellant Production Unit,” Report to NASA, Lyndon B. Johnson Space Center under Contract NAS 9-97082, 1997. 
Abundance

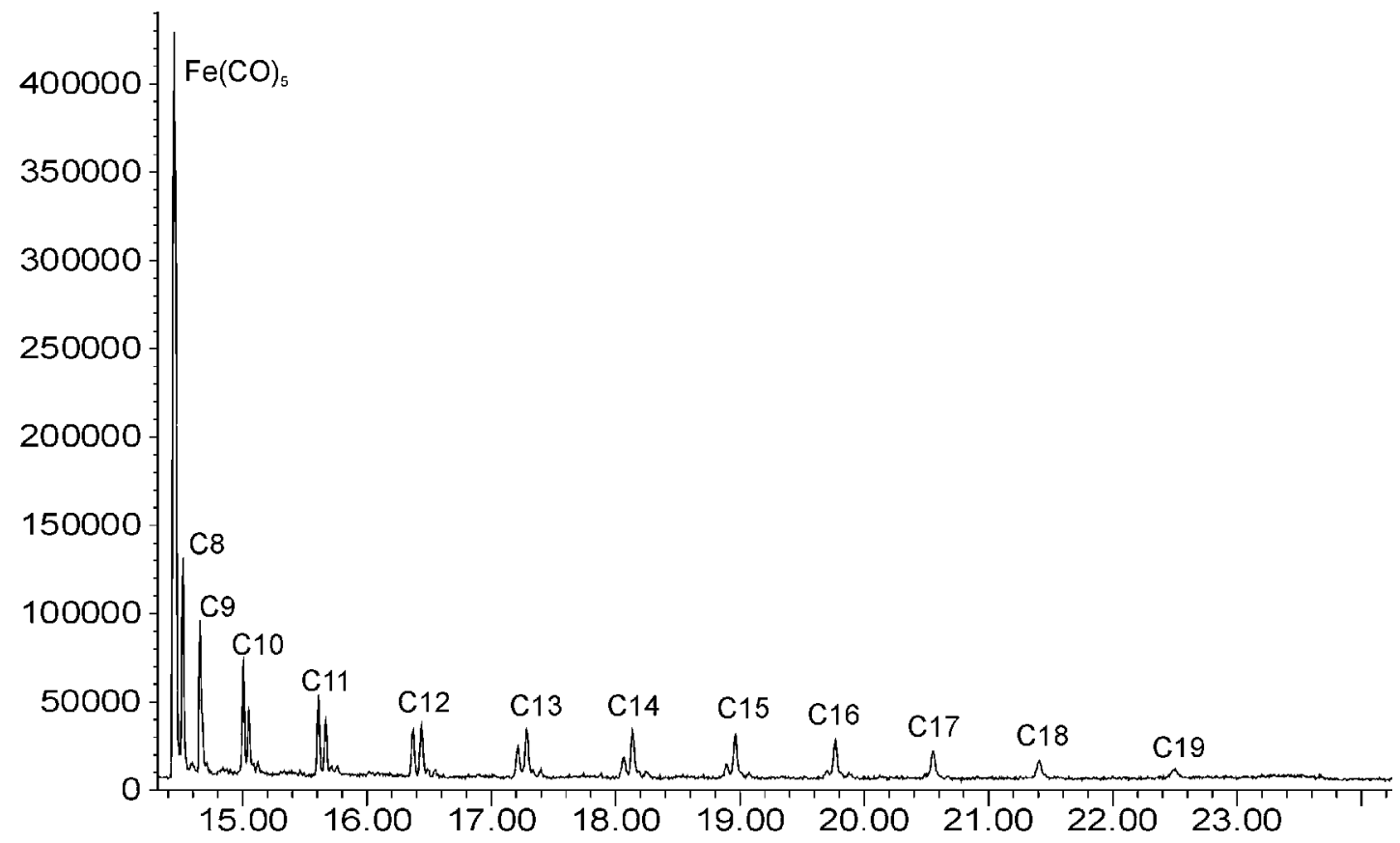

Time-->

Figure 1. Total ion chromatogram from initial start up experiment with 0.3 mol cobalt loaded xerogel. The first peak results from a high level of iron carbonyl. Split peaks indicate the

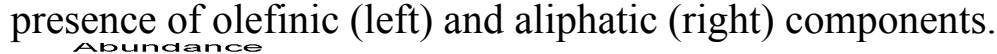

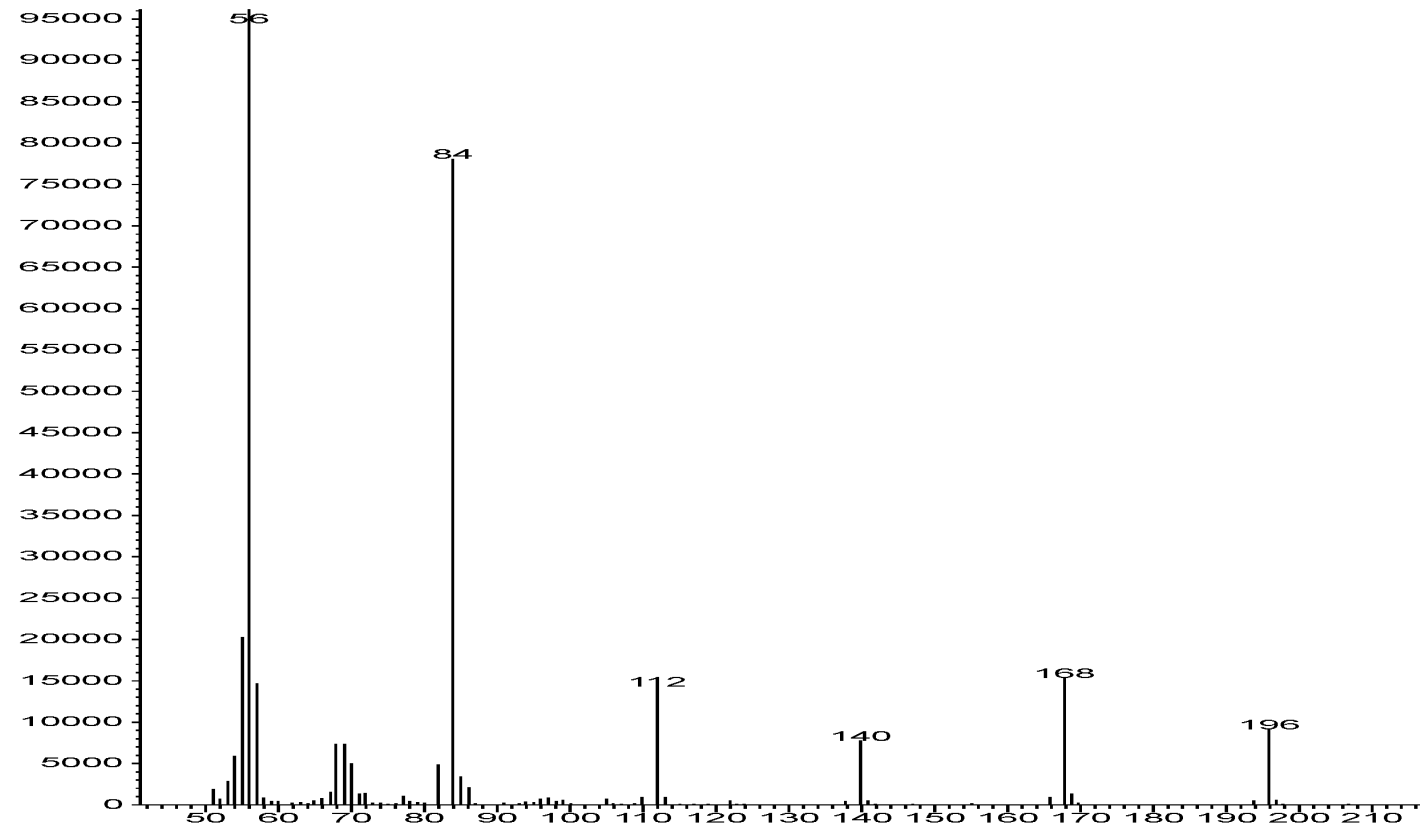

Figure 2. Unknown spectrum from the largest peak in Figure 1. This corresponds to iron pentacarbonyl. 


\section{Supercritical Fluids as Reaction Medium for Fischer-Tropsch Synthesis}

Xiwen Huang, Nimir O. Elbashir, Christopher B. Roberts. Auburn University

Fischer-Tropsch synthesis (FTS) holds great potential for the alternative production of ultra-clean transportation fuels, chemicals, and other hydrocarbon products through the conversion of readily available syngas $\left(\mathrm{CO} / \mathrm{H}_{2}\right)$ resources. The traditional FTS process, either gas phase or liquid phase, inevitably involve mass transfer or heat transfer limitations. As a result of supercritical fluids (SCFs) unique gas-like transport properties or liquid-like solubilities, they offer several advantages over traditional solvents as reaction media in the FTS process. These advantages include increased production of valuable products and alleviation of catalyst plugging as a result of the enhanced heat transfer capability and heavy products solubility as well as increased $\mathrm{CO}$ conversion.

Our research group has been conducting a systematic investigation of the influence of the supercritical fluids media on FTS reactions in a continuous, high-pressure reactor by employing a traditional Co catalyst. We have demonstrated promising results in supercritical hexane FTS in that steady state operation was quickly achieved, a higher syngas conversion was obtained and the hydrocarbon product distribution was shifted to higher carbon number products. In addition, increased 1-olefin selectivity was obtained in the SCF phase reaction.

Over the last six months, we have been using supercritical pentane as the reaction medium. Pentane has a lower critical temperature $\left(197^{\circ} \mathrm{C}\right)$ with similar physical properties as that of hexane. A wider temperature range can be set up for the kinetics study while the medium properties can be kept the same as that in hexane medium by simple pressure adjustments. We have employed a detailed investigation of the reaction behavior in supercritical pentane FTS for the purpose of exploring the optimum reaction strategy for SCF-FTS. Some of these results are summarized below:

CO conversion:

An increase in the temperature from $210^{\circ} \mathrm{C}$ to $250^{\circ} \mathrm{C}$ with a constant reaction pressure and syngas flowrate leads to an increase in CO conversion from $40 \%$ to $90 \%$. However the productivity of undesirable $\mathrm{CH}_{4}, \mathrm{CO}_{2}$ and other light compounds also increase at the higher temperature. These results reveal the existence of a favorable reaction temperature range for lower productivity of undesirable products and high $\mathrm{CO}$ conversion. $\mathrm{CO}$ conversion increases with increases in reaction pressure within a certain pressure range (600psi 1000psi), which is similar to our previous results in supercritical hexane. However, we did not observe a pressure within our experimental pressure range $(<1000 \mathrm{psi})$ that corresponded to a maximum in conversion and investigation of a wider pressure range is necessary. Changes in syngas space velocity impart no noticeable effect on the $\mathrm{CO}$ conversion such that changes in external diffusion resistance could not impose a significant impact on the $\mathrm{CO}$ conversion. $\mathrm{CO}$ conversion is mainly dependent on $\mathrm{CO}$ the adsorption rate and the active site accessibility for $\mathrm{CO}$ adsorption. 1-olefins selectivity:

1-olefin selectivity is very sensitive to temperature changes with high 1-olefins selectivity at low reaction temperature. The disappearance of heavy 1-olefins at high reaction temperature is not believed to be resulted from its improved re-adsorption onto the carbon chain, but rather from its increased hydrogenation or isomerization rate at high temperature. This was observed through increased 2-olefins production and decreased heavy hydrocarbons content at high temperature. A moderate increase in the reaction pressure can also facilitate the production of 1- 
olefins. The increased pressure driven enhanced extraction plays a very important role in the 1olefins selectivity.

Experiments performed at constant medium density and temperature in hexane and pentane (different pressures) resulted in much higher conversions in pentane (high pressure), $92 \%$, than in hexane (lower pressure), $61 \%$. Even with this drastic difference in conversion in the two constant density solvent systems, the 1-olefins selectivity remained essentially unchanged.

Production Distribution:

Low reaction temperature favors the formation of more heavy hydrocarbons. The overall product distribution exhibits non-ASF distribution, due to the re-adsorption of 1-olefins. A decrease in chain growth probability was observed as temperature increased. Under high temperature operation, the reaction pressure effect on the heavy hydrocarbons content was significant, while there was less effect of pressure increases on the hydrocarbon yield and carbon chain growth probability under low temperature operation. Lower $\mathrm{H}_{2} / \mathrm{CO}$ ratio in the feed lead to higher chain growth probability and heavier hydrocarbon production. This result is agreement with literature observations in gas phase FTS. Changes in syngas flowrate had little influence on the carbon chain growth probability as evidenced by an unnoticeable effect on the $<\mathrm{C} 20$ range hydrocarbon products, suggesting that the process in not externally diffusion controlled. However, increases in syngas flowrate resulted in decreases in $\mathrm{C} 20+$ products.

Publications and Presentations from 2002-2003:

1. Xiwen Huang, Nimir O. Elbashir, Christopher B. Roberts. Supercritical Pentane Phased Fischer-Tropsch Synthesis: Process Conditions Effects on Product Distribution. Ind. Eng. Chem. Res. (To be submitted)

2. Xiwen Huang, Nimir O. Elbashir, Christopher B. Roberts. CO conversion and 1-olefins selectivity in supercritical pentane phase Fischer-Tropsch Synthesis. Fuel. (To be submitted)

3. Xiwen Huang, Christopher B. Roberts. Selective Fischer-Tropsch Synthesis over an $\mathrm{Al}_{2} \mathrm{O}_{3}$ Supported Cobalt Catalyst in Supercritical Hexane. Fuel Processing Technology, 2003(in press)

4. Xiwen Huang, Christine W. Curtis, Christopher B. Roberts. Reaction Behavior of FischerTropsch Synthesis in near-critical and supercritical hexane Medium. Fuel Chemistry Division Preprints, 2002,47(1),150

5. Xiwen Huang, Nimir O. Elbashir, Christopher B. Roberts. Fischer-Tropsch Synthesis over Cobalt catalyst in Supercritical Hexane: Comparative Study with the FT Gas Phase Reaction. AIChE Annual Meeting, Indianapolis, 2002.

6. Xiwen Huang, Christine W. Curtis, Christopher B. Roberts. The Fischer-Tropsch Synthesis in Supercritical Medium. AIChE Annual Meeting, Reno, NA, 2001

7. Xiwen Huang, Christine W. Curtis, Christopher B. Roberts. Reaction behavior of FischerTropsch synthesis in near critical and supercritical hexane media. 223rd ACS National Meeting, Orlando, FL, April 7-11, 2002, 


\section{Microporous Shape-Selective Catalysts and Processes for Ethylene, Propylene and other Value-Added Products via C-1 Chemistry}

Delphine R. Dubois, Daniel L. Obrzut, Jing Liu, Jyothi Thundimadathil, Prakash M. Adekkanattu, James A. Guin

Chemical Engineering Department, Auburn University

We have investigated silicoaluminophosphate molecular sieves synthesized by hydrothermal procedures (SAPO-34) modified with transition metals $\mathrm{Co}, \mathrm{Mn}$, and $\mathrm{Ni}$ for their activity, selectivity, and lifetime in the methanol to olefins reaction and compared with that of unmodified versions ${ }^{1}$. The crystallinity, phase purity and morphology of the materials were confirmed by X-ray powder diffraction and scanning electron microscope. Drs. Seehra and Punnoose at West Virginia University determined the electronic state and location of the metal ions in these materials by magnetic measurements. Their magnetic studies showed that for MnSAPO-34, CoSAPO-34 the metal ions are incorporated into the SAPO framework with concentrations $\simeq 0.12$ and $0.17 \mathrm{wt} \%$, respectively. For nickel modified SAPO-34 samples prepared by two different procedures, their magnetic studies showed the presence of either nanoparticles ( $\mathrm{Ni}$ or $\mathrm{NiO}$ ) outside the SAPO framework or nickel ions incorporated into the SAPO framework. Although the total C2-C4 olefins activity on these materials was comparable to that of unmodified SAPO-34, significant variations in the deactivation behavior were observed among various metal modified catalysts. MnSAPO-34 was found to be the best catalyst based on catalyst lifetime. In the case of Ni-SAPO-34 unusually high amounts of methane formed due to the nanoparticles outside the SAPO framework.

In an attempt to reduce methane formation and thereby to enhance the lower olefins selectivity, SAPO-34 catalyst was modified either by alkali, transition, or rare-earth metals including Ce, Cs, Mo, and Ag. These modified catalysts were then tested. The effect of temperature on methane formation was studied between $300{ }^{\circ} \mathrm{C}$ and $500{ }^{\circ} \mathrm{C}$. These metal modified catalysts produced interesting results at higher temperatures, especially $500{ }^{\circ} \mathrm{C}$. Compared to a SAPO-34 catalyst that normally produces very high methane at this temperature, the $\mathrm{Ce}, \mathrm{Cs}$ and $\mathrm{Ag}$ modified catalysts reduced methane production by roughly $50 \%$. Only molybdenum modified SAPO-34 produced more methane at $500{ }^{\circ} \mathrm{C}$ than unmodified SAPO-34.

SAPO-56 is a more recent and novel silicoaluminophosphate. We have prepared nickel substituted and unsubstituted silicoaluminophosphate molecular sieves of type 56 (SAPO-56 and NiSAPO-56) hydrothermally using N,N,N',N'-tetramethyl hexane 1,6-diamine as the structure directing agent. These materials were characterized by X-ray powder diffraction and scanning electron microscopy. The SAPO-56 samples prepared with varying silicon contents showed different crystal morphologies including new "doughnut" morphology. The catalytic performance of both SAPO-56 and NiSAPO-56 was studied in methanol to olefins reactions. Methanol conversion was 100 percent on both SAPO-56 and NiSAPO-56 at high temperatures and also at low methanol flow rates. The NiSAPO-56 shows some increases in ethylene and $\mathrm{C}_{2-}$ $\mathrm{C}_{4}$ olefins selectivities compared to SAPO-56. The overall activity of SAPO-56 and NiSAPO-56 is lower than SAPO-34, but comparable with other small pore SAPO molecular sieves. For SAPO-56 samples prepared with varying silicon concentrations, the lifetimes tend to decrease with increased silicon content. No significant effect on product selectivities with variation in silicon content was observed. Both SAPO-56 and NiSAPO-56 showed longer lifetimes and higher $\mathrm{C}_{2}-\mathrm{C}_{4}$ olefins selectivities at $350{ }^{\circ} \mathrm{C}$. At higher temperatures both SAPO-56 and NiSAPO56 produced increased amounts of methane and decreased $\mathrm{C}_{2}-\mathrm{C}_{4}$ selectivity. 
A reactor system to perform direct syngas conversion was built. This involved installing a stainless steel reactor and a furnace into a fume hood. New piping and fittings were installed. Gas flow controllers were recalibrated to handle lower flowrates more precisely. Solenoid valves controlled by gas detectors were installed as a safety measure. We expect to begin testing of this new system shortly with metal modified SAPO's.

1. Delphine R. Dubois, Daniel L. Obrzut, Jing Liu, Jyothi Thundimadathil, Prakash M. Adekkanattu, James A. Guin, Alex Punnoose and Mohindar S. Seehra, "Conversion of Methanol to Olefins over Cobalt, Manganese and Nickel Incorporated SAPO-34 Molecular Sieves" accepted for publication in a Special Issue on "Advances in C1 Chemistry", Fuel Processing Technology, 2003. 


\section{Dry Reforming of Methane To Synthesis Gas With Tungsten Carbide Catalyst}

Huifang Shao, Lawrence Norcio, Edwin L. Kugler, and Dady B. Dadyburjor

Department of Chemical Engineering, West Virginia University

\section{Introduction}

Many industrial processes use methane as a primary feedstock for producing a mixture of carbon monoxide and hydrogen, called synthesis gas (syngas). The syngas serves as the feedstock for a variety of downstream processes, such as methanol synthesis, Fischer-Tropsch synthesis or ammonia synthesis [1]. There are three ways to produce syngas, which are:
1) steam reforming:
$\mathrm{CH}_{4}+\mathrm{H}_{2} \mathrm{O} \rightarrow \mathrm{CO}+3 \mathrm{H}_{2}$
2) partial oxidation:
$\mathrm{CH}_{4}+1 / 2 \mathrm{O}_{2} \rightarrow \mathrm{CO}+2 \mathrm{H}_{2}$
3) dry reforming:
$\mathrm{CH}_{4}+\mathrm{CO}_{2} \rightarrow 2 \mathrm{CO}+2 \mathrm{H}_{2}$

Dry reforming is the focus of this research. Traditional, nickel-based catalysts have some unavoidable shortcomings. Coke formation on nickel surfaces is a major problem that causes catalyst deactivation. Certain molybdenum and tungsten carbide catalysts offer a possible solution to this problem by being able to dissolve excess surface-carbon into its bulk to keep the surface clean. When carbon is soluble within catalytic materials, thermodynamics will determine catalyst phase and the fate of excess carbon. Hence, carbon accumulation can be prevented by choice of operating conditions. Here, tungsten-cobalt carbides are being prepared for study as dry reforming catalysts.

\section{Catalyst Precursor Synthesis}

14.5 grams of tungstic acid, $\mathrm{H}_{2} \mathrm{WO}_{4}$, were added to a mixture containing $400 \mathrm{ml}$ of X molar $\mathrm{NH}_{4} \mathrm{OH}$ solution and $300 \mathrm{ml}$ of ethylenediamine, followed by heating to $50^{\circ} \mathrm{C}$ and stirring to get a clear solution. 13.5 grams of $\mathrm{CoCl}_{2} \cdot 6 \mathrm{H}_{2} \mathrm{O}$ were dissolved in distilled water and added into the above solution. A precipitate, $\mathrm{Co}(\mathrm{en})_{4} \mathrm{WO}_{4}$, formed when the volume of the mixture was reduced to $300 \mathrm{ml}$ by evaporating and slow overhead stirring. The product was then filtered, washed and dried for thermodynamically-controlled decomposition as shown below. [2,3].

\section{Decomposition of Precursor}

Cobalt-tungsten carbides are produced by decomposing $\mathrm{Co}(\mathrm{en})_{4} \mathrm{WO}_{4}$ in a $\mathrm{CO}_{2}-\mathrm{CO}$ mixture. The oxidizing potential of the mixture, determined by pressure and $\mathrm{CO}_{2}$-to- $\mathrm{CO}$ ratio, provides thermodynamic control for the carbide phases formed. Prof. Seehra's group at WVU made the x-ray powder diffraction (XRD) measurements used to identify the decomposition products.

The XRD patterns of materials produced with different $\mathrm{CO}_{2}$-to- $\mathrm{CO}$ ratios are compared in Figure 1. A ratio of 0.1 produced a mixture of $\mathrm{WC}$ and metallic cobalt (shown in curve a) with a broad band at 20 degrees-2-theta produced by amorphous carbon. This pattern is similar to the $\mathrm{XRD}$ pattern of a very active catalyst described in Iyer's work [4]. Increasing the $\mathrm{CO}_{2}$-to-CO ratio to 0.2 produced a mixture of $\mathrm{Co}_{6} \mathrm{~W}_{6} \mathrm{C}$ and WC. Stochiometry requires metallic cobalt be present in addition to the carbides identified in curve b. $\mathrm{A} \mathrm{CO}_{2}$-to- $\mathrm{CO}$ ratio of 0.5 produced the $\mathrm{Co}_{6} \mathrm{~W}_{6} \mathrm{C}$ product identified in curve $\mathrm{c}$. A higher ratio of 0.75 also produced $\mathrm{Co}_{6} \mathrm{~W}_{6} \mathrm{C}$ but there are additional lines in curve $\mathrm{d}$ that are not identified. These could be produced by an oxide.

This series of XRD patterns show that nearly pure $\mathrm{Co}_{6} \mathrm{~W}_{6} \mathrm{C}$ can be produced by using a $\mathrm{CO}_{2} / \mathrm{CO}$ ratio of 0.5 and that a $\mathrm{Co}-\mathrm{WC}-\mathrm{C}$ mixture can be produced using a ratio of 0.1 . 


\section{Reaction Studies}

Previous studies by Iyer [4] showed that a very active catalyst could be produced by reacting $\mathrm{CH}_{4}$ and $\mathrm{CO}_{2}$ with a $\mathrm{Co}_{6} \mathrm{~W}_{6} \mathrm{C}$ catalyst at $850{ }^{\circ} \mathrm{C}$ for a 24-hour period. At end-of-run, the material removed from the reactor was no longer $\mathrm{Co}_{6} \mathrm{~W}_{6} \mathrm{C}$ but a Co-WC-C mixture with an XRD pattern similar to the one shown in Figure 1a.

We are currently modifying the reactor system and the preparation techniques. We have found that the mode of stirring influences the uniformity of the catalyst precursor formed. The reactor is being modified to reduce pressure drop through the catalyst bed. Other changes will permit independent analysis of the feed mixture. This will improve extent of reaction and material balance calculations. Reaction studies with materials synthesized using different $\mathrm{CO}_{2^{-}}$ to-CO ratios will be evaluated for methane reforming. The $\mathrm{Co}-\mathrm{WC}-\mathrm{C}$ mixture produced with the $0.1 \mathrm{CO}_{2}$-to-CO ratio is of particular interest.

V. Recent Publications

1. "Catalysis for Synthesis Gas Formation from Reforming of Methane" M.V.Iyer, L.P. Norcio, A. Punnoose, E.L. Kugler, M.S. Seehra and D.B. Dadyburjor, Topics in Catalysis, submitted.

2. "Kinetic Modeling for Methane Reforming with Carbon Dioxide over a Mixed-Metal Carbide Catalyst," M.V. Iyer, L.P. Norcio, E.L. Kugler, and D.B. Dadyburjor, Ind. Eng Chem. Res., accepted.

VI. Invited Presentation

1. "Synthesis-Gas Formation from Reforming of Methane," 16th National Symposium and $1^{\text {st }}$ Indo-German Conference on Catalysis, February 6, 2003, Hyderabad, INDIA.

\section{$\underline{\text { References }}$}

1. J. B. Claridge, A. P. E. York, A. J. Brungs, C. Marquez-Alvarez, J. Sloan, S. C. Tsang, M. L. H. Green, J. Catal. 180, 85 (1998).

2. R. S. Polizzotti, L. E. McCandlish, \& E. L. Kugler, Multiphase Composite Particle Containing a Distribution of Nonmetallic Compound Particles. US Patent 5,338,330, August 16, 1994.

3. E. L. Kugler, L. E. McCandlish, A. J. Jacobson, R. R. Chinaselli, Eta Phase Materials, Methods of Producing the Same, and Use Thereof as Catalyst for Alcohol Synthesis, Hydrocarbon Synthesis, Hydrocarbon Hydrogenation and Hydrocarbon Conversion. US Patent 5,138,111, August 11, 1992.

4. M Iyer, MSChE Thesis, West Virginia University, December 2001. 


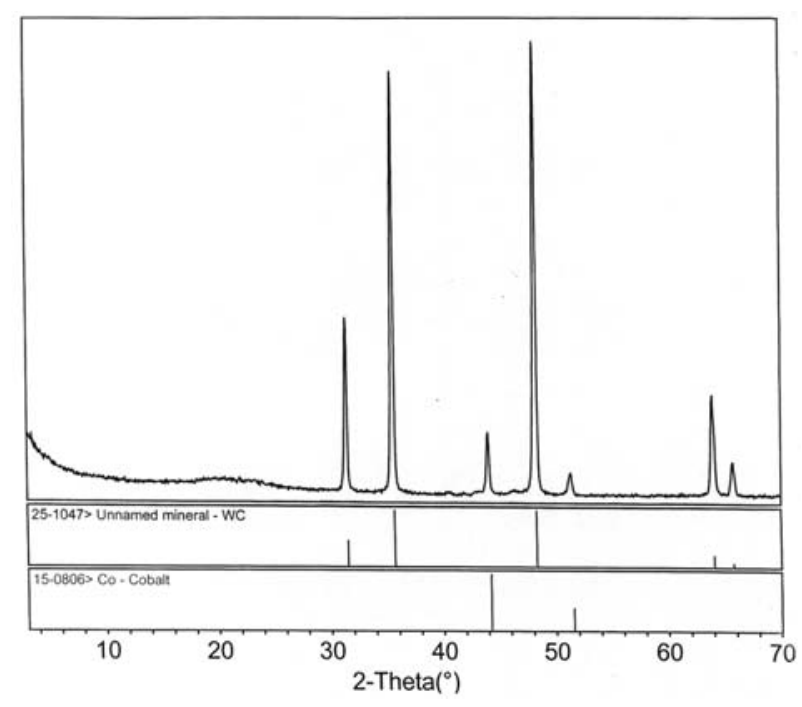

(a)

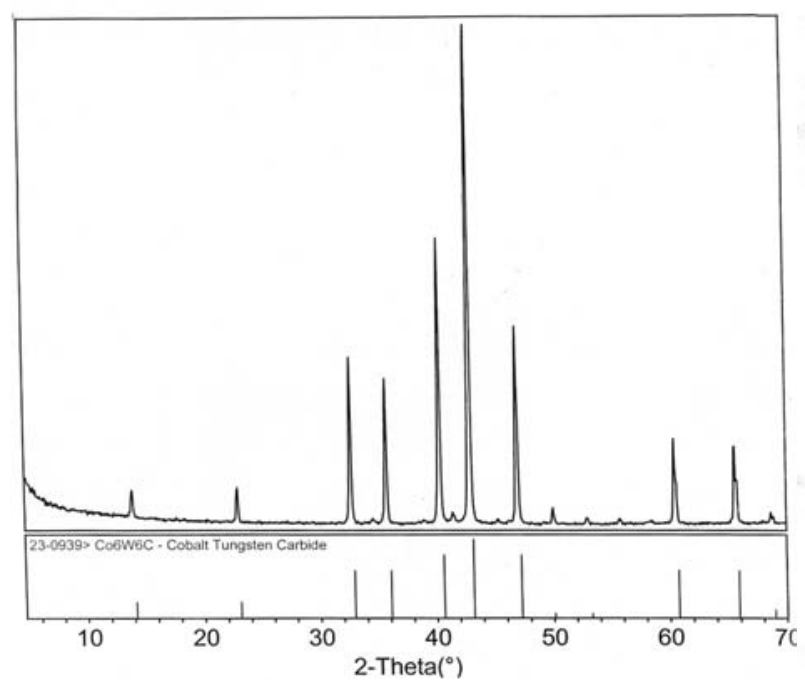

(c)

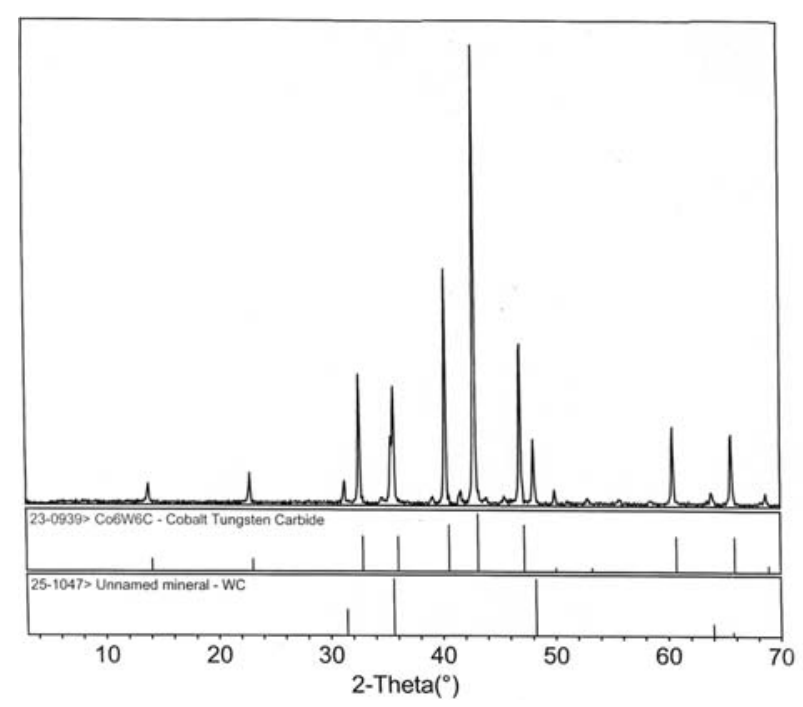

(b)

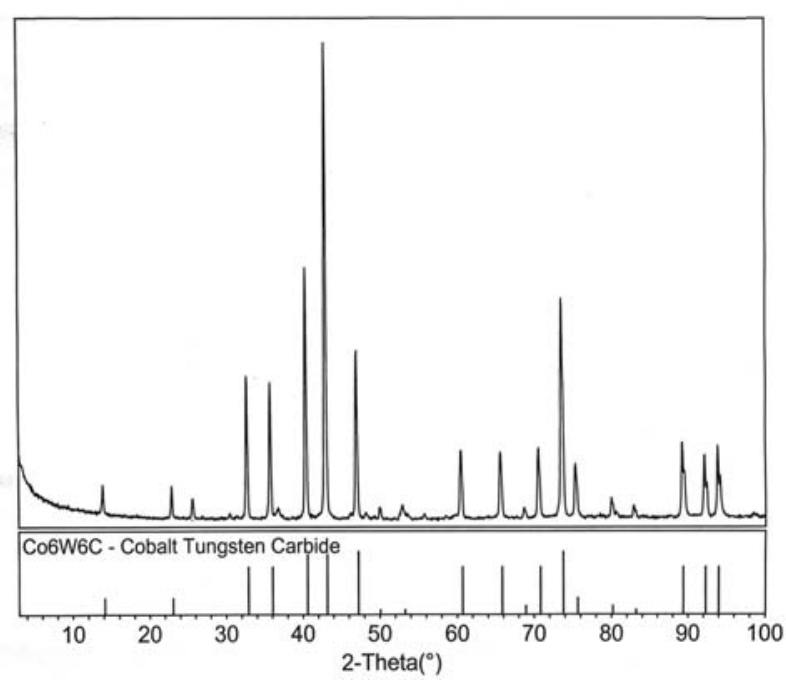

(d)

Figure 1. XRD patterns of $\mathrm{Co}-\mathrm{W}$ carbides prepared at $850{ }^{\circ} \mathrm{C}$ with differing $\mathrm{CO}_{2}$-to-CO ratios. a: $\mathrm{CO}_{2} / \mathrm{CO}=0.1 ; \mathrm{b}: \mathrm{CO}_{2} / \mathrm{CO}=0.2 ; \mathrm{c:} \mathrm{CO}_{2} / \mathrm{CO}=0.5 ; \mathrm{d}: \mathrm{CO}_{2} / \mathrm{CO}=0.75$ 


\section{Synthesis of Hydrocarbons and Alcohols From Syngas}

Brian A. O'Palko, Edwin L. Kugler, and Dady B. Dadyburjor

Department of Chemical Engineering, West Virginia University

\section{Catalyst Characterization.}

The temperature-programmed reduction (TPR) experimental setup has been rebuilt. We used the TPR in the past to characterize the valence states of alcohol synthesis catalysts and to identify the states associated with catalytic activity. The new set-up has eliminated the dead space and voids that were in the old system. Further, an additional thermocouple has been placed within the catalyst sample for a more accurate reading of sample temperature. Finally, all gas cylinders have been moved and secured against an outside wall for safer operation. The result is that the peaks obtained from the thermal conductivity detector (TCD) are now sharper. Sharper peaks are easier to deconvolute and allow us to be more accurate when determining reducing temperatures.

The TPR equipment was validated with copper(II) oxide standards and well as several tungsten-on-carbon catalyst samples. A comparison of data from the new and prior experimental setup is provided in Figure 1. Notice that the peaks obtained with new setup have sharper features than were observed previously. Note that the greater accuracy in the peak positions allows us to identify features not seen earlier.

Collaboration with Brookhaven National Laboratory in Upton, NY has been initiated. In November 2002, we spent 4 days conducting research at the National Synchrotron Light Source at BNL. We learned how to operate time-resolved diffraction equipment where changes in x-ray diffraction pattern can be recorded during chemical reaction. We ran temperature-programmed reduction experiments on a $\mathrm{W} / \mathrm{C}$ calcined sample and a $\mathrm{W}-\mathrm{K} / \mathrm{C}$ calcined sample while recording $\mathrm{x}$-ray diffraction data. These samples contained $18 \%$ by weight tungsten from an ammonium tungstate source. We conducted temperature-programmed reduction experiments on $\mathrm{Co}_{6} \mathrm{~W}_{6} \mathrm{C}$ samples in support of the methane reforming project, also.

An example of time-resolved $x$-ray diffraction measurements are shown in Figure 2 for a tungsten-on-carbon sample, abbreviated as $\mathrm{W} / \mathrm{C}$. A temperature programmed reduction experiment was run to $925{ }^{\circ} \mathrm{C}$ while measuring the diffraction pattern. Figure 2 shows the reduction of tungsten oxides to metallic tungsten. Near the end of reduction, some metallic tungsten is converted to tungsten carbide.

We are traveling back to BNL on March 18, 2003 to conduct experiments for three days. This project has been allotted 30 days of experimental time between September 1, 2002 and August 31, 2004. 
Figure 1. TPR Spectrum of Calcined W/C Catalyst

Solid Line - New Setup; Dotted Line - Old Seup

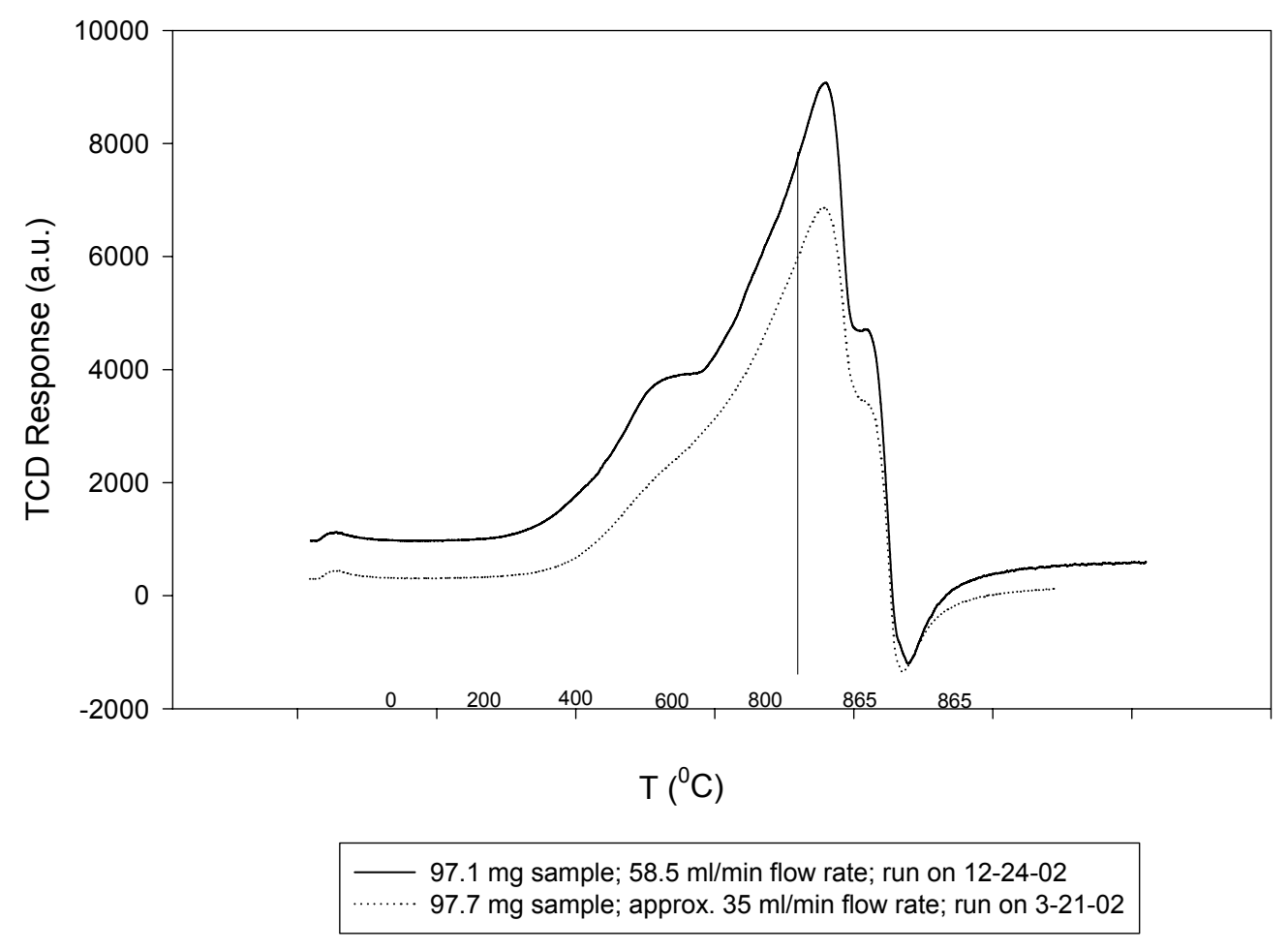

wc122402_wc18calc 


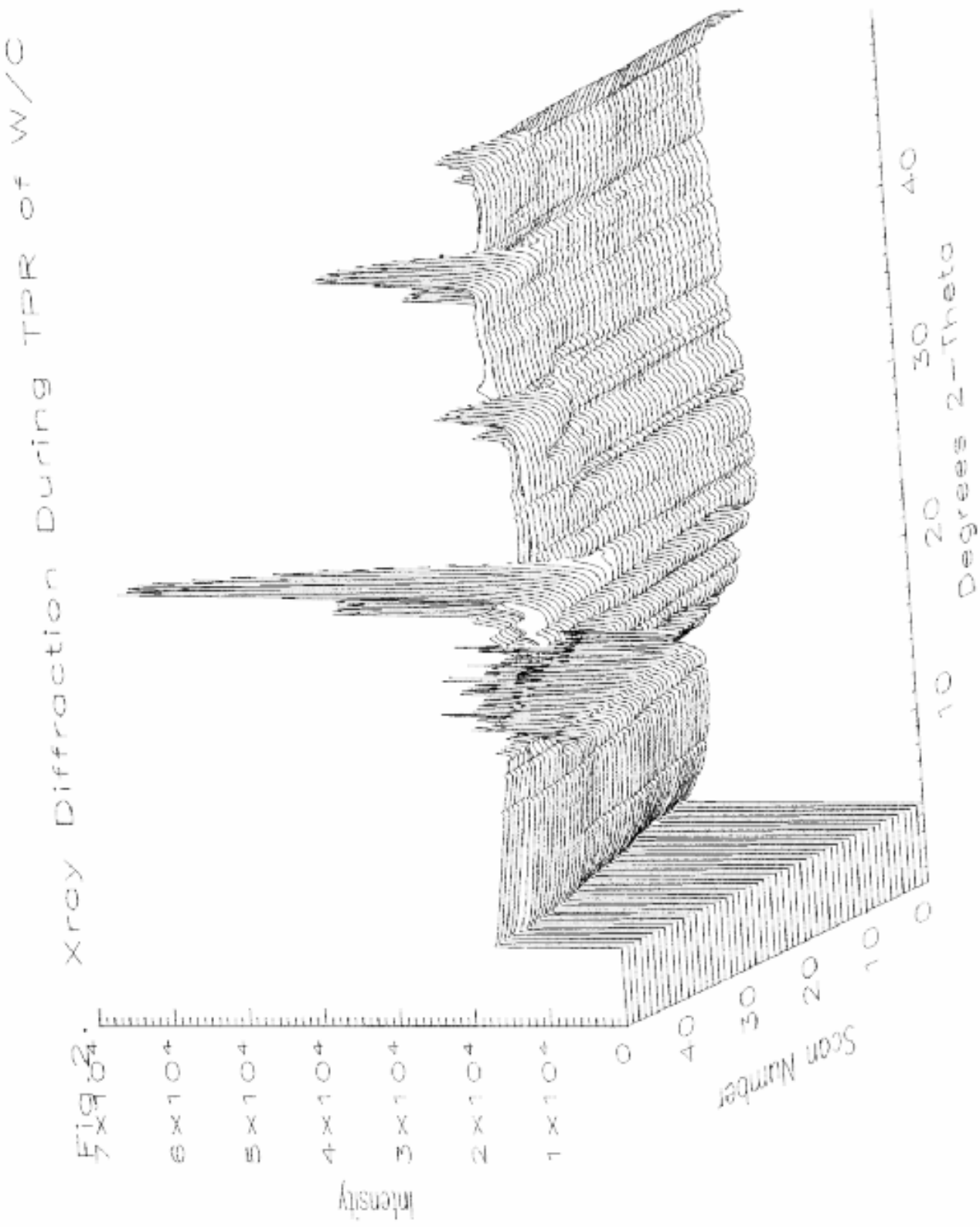




\section{Hydrogen production by catalytic decomposition of ethane and propane Naresh Shah, Yuguo Wang, and Gerald P. Huffman \\ University of Kentucky}

Non-oxidative, catalytic decomposition of hydrocarbons is an alternative, one-step process to produce pure hydrogen. Nanoscale, binary Fe-based catalysts supported on high surface area alumina $\left(\mathrm{M}-\mathrm{Fe} / \mathrm{Al}_{2} \mathrm{O}_{3}, \mathrm{M}=\mathrm{Mo}, \mathrm{Pd}\right.$ or $\left.\mathrm{Ni}\right)$ have shown high activity for the catalytic decomposition of undiluted methane into pure hydrogen $\left[^{1}\right]$. One of the problems with nonoxidative dehydrogenation is coking of the catalyst and reactor due to carbon build up. Under proper reaction conditions, these binary catalysts promote the growth of carbon nanotube structures which transports carbon away from the catalyst surfaces, thereby increasing the hydrogen production as well as producing a potentially valuable by-product.

Ethane, a constituent of natural gas and a byproduct of cracking and fractional distillation of petroleum can also serve as a hydrocarbon feed stock to produce pure hydrogen. Ethane is also present in significant amounts in the Fischer-Tropsch reaction products. Non-catalytic steam cracking of ethane has been commercially used for production of ethylene $\left[{ }^{2}\right]$ at reaction conditions of high $(>800 \mathrm{C}$ ) temperature and short contact times. However, an oxidative catalytic dehydrogenation process $\left[3,4,6,{ }^{3},{ }^{8}\right]$ is preferred due to lower temperatures, better process control and higher ethylene yields. In both of these processes, even in the presence of an oxidizing atmosphere, unintended carbon build up and subsequent coking and fouling of the reactor occurs. Special coatings to reduce this carbon build up are required $\left.{ }^{9}\right]$. Because of the oxidative atmosphere, invariably, major portions of the extracted hydrogen are lost in the process as water.

Propane is normally produced during hydrocracking processes at refineries. There are two principle uses of propane: (1) as a feedstock to produce acrylic or propenoic $(\mathrm{CH} 2=\mathrm{CHCO} 2 \mathrm{H})$ acid by partial oxidation; and (2) as a fuel for residential cooking and heating. There is an established network of propane distributors throughout the country for selling and refilling propane tanks.

In this work, the activity of the same binary catalysts for the catalytic cracking of undiluted ethane is investigated. Some preliminary work on propane dehydrogenation is also reported.

\section{Ethane dehydrogenation}

As shown in figure 1 , these binary catalysts are also very effective in promoting decomposition of ethane. In non-catalytic, thermal decomposition, active acidic sites on alumina support break $\mathrm{C}-\mathrm{H}$ bonds to produce ethylene and hydrogen. The binary catalysts have to be pre-reduced in hydrogen to generate active metallic species responsible breaking $\mathrm{C}-\mathrm{C}$ bonds.

At around $500 \mathrm{C}$, these catalysts start breaking $\mathrm{C}-\mathrm{C}$ bonds in ethane to generate methane and hydrogen in substantial quantities. Some carbon is deposited as nanotubes with "stacked traffic cones" morphology. At temperatures of 650C and above, all of the ethane reacts to generate mostly hydrogen and some methane. In our previous work we have demonstrated that these catalysts are also very effective in methane decomposition. Hence the methane generated due to $\mathrm{C}-\mathrm{C}$ bond cleavage immediately undergoes further decomposition to generate additional hydrogen and multi-walled nanotubes. Figure 2 shows the two kinds of nanotubes produced by the same catalyst used for ethane decomposition at 500C and $650 \mathrm{C}$ reactor temperatures 


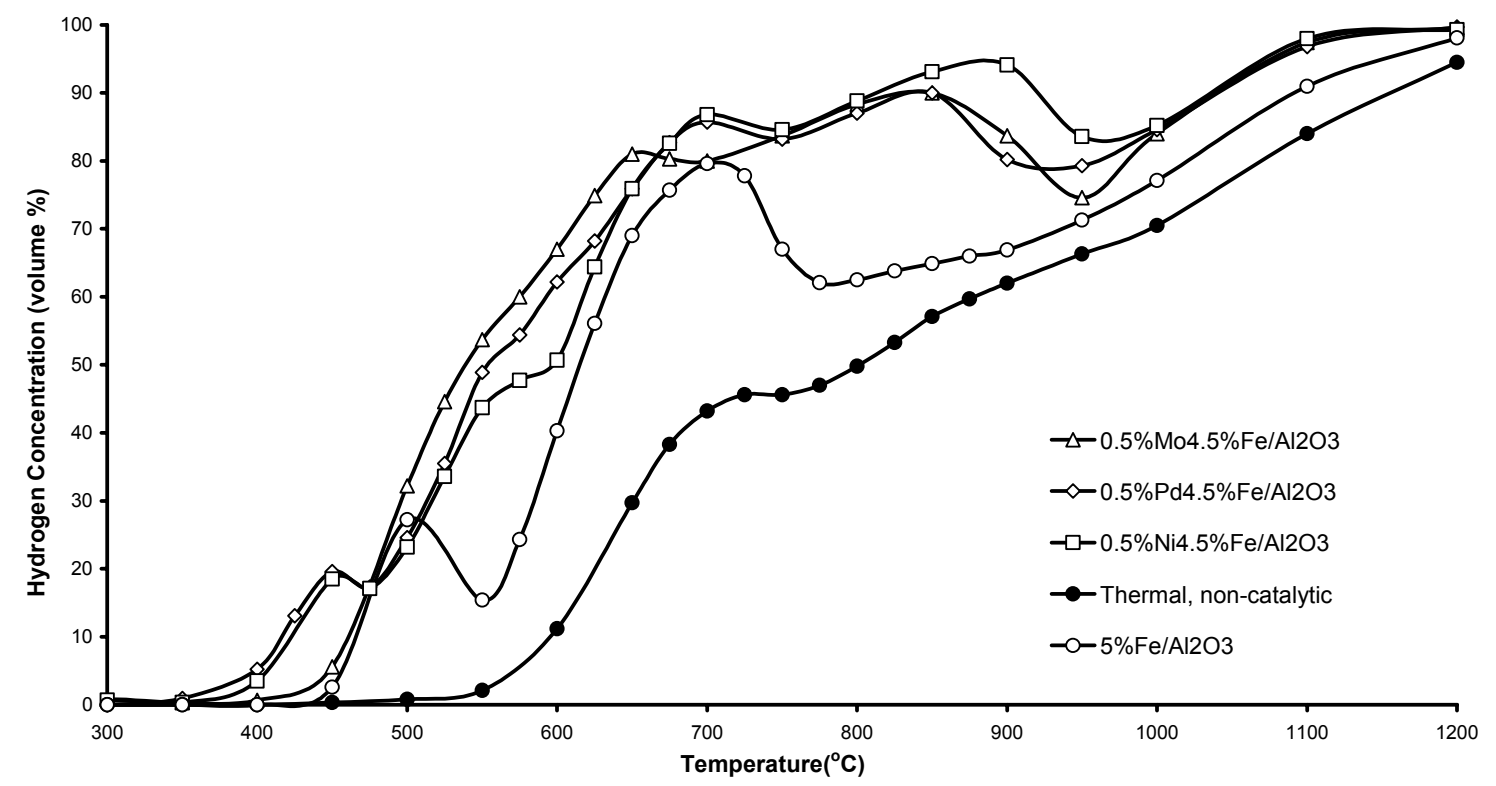

Figure 1. Hydrogen production from thermal (non-catalytic) and catalytic cracking of ethane.
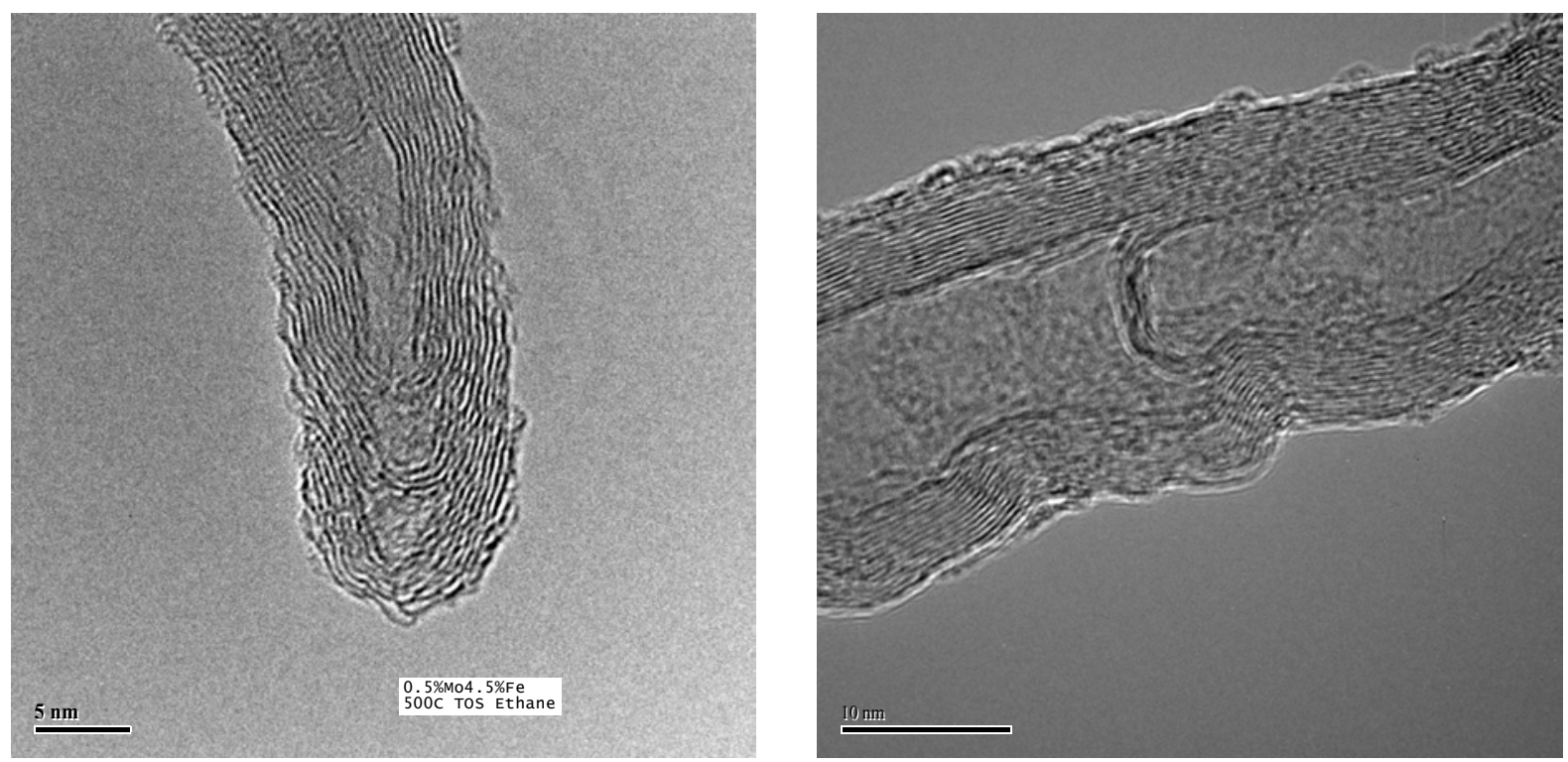

Figure 2. HRTEM images of carbon nanotubes generated on $(0.5 \% \mathrm{Mo}-4.5 \% \mathrm{Fe}) / \mathrm{Al} 2 \mathrm{O} 3$ catalyst used for ethane dehydrogenation. Reactor temperatures were $500 \mathrm{C}$ (left) and $650 \mathrm{C}$ (right)

\section{Propane dehydrogenation}

As for methane and ethane dehydrogenation experiments, the same binary catalysts were pre-reduced in-situ under the same conditions before studying the effect of reactor temperature on propane decomposition.

In thermal, non-catalytic runs, propane decomposition is first noted at temperatures above $525 \mathrm{C}$ in form of a small amount of hydrogen production. With increasing temperature, the amounts of hydrogen, methane, ethylene and ethane all increase till reactor temperature is above 
650C. At higher temperatures, secondary decompositions of methane, ethane and ethylene also start occurring to yield additional hydrogen. Complete propane decomposition occurs only at reactor temperatures above $750 \mathrm{C}$. Similar trends were observed for a $5 \% \mathrm{Fe} / \mathrm{Al} 2 \mathrm{O} 3$ catalyst prereduced at $700 \mathrm{C}$. We have previously noted that a $700 \mathrm{C}$ pre-reduction temperature was not effective for this monometallic catalyst. It is worth noting that no peaks due to propene, acetylene, benzene, or higher hydrocarbons were observed for any of the catalysts and reaction conditions.

Binary catalysts reduced at $700 \mathrm{C}$ initiate the decomposition of propane at $400 \mathrm{C}$ to produce hydrogen and methane. Almost $100 \%$ of the propane is converted to approximately $70 \%$ hydrogen and $30 \%$ methane at temperatures above $525 \mathrm{C}$. 


\title{
XAFS and Mössbauer Investigation of Catalysts
}

\author{
Frank E. Huggins, Naresh Shah, Yuguo Wang, and Gerald P. Huffman
}

University of Kentucky

\section{Fe-Mo catalysts for hydrogen production from methane:}

There is currently significant activity in the Consortium in designing and improving catalysts for the direct decomposition of methane to carbon and hydrogen (Shah et al., this report). Currently under investigation are binary ferrihydrite catalysts supported on alumina. For each $95 \%$ by weight of $\mathrm{Al}_{2} \mathrm{O}_{3}$, there is $4.5 \%$ by weight of $\mathrm{Fe}^{3+}$ and $0.5 \%$ by weight of a second element, typically $\mathrm{Ni}^{2+}, \mathrm{Pd}^{2+}$ or $\mathrm{Mo}^{6+}$. In previous years, we have examined these catalysts and their activity at three distinct stages: (i) as prepared; (ii) after a 2 hour reduction pre-treatment in hydrogen at various temperatures; and (iii) after exposure to methane at various temperatures for various times. The techniques used to examine these catalysts included XAFS spectroscopy for Fe, Ni, Pd and Mo and Mössbauer spectroscopy for Fe. Highlights of such studies included the recognition of the significance of hercynite, $\mathrm{Fe}_{2} \mathrm{Al}_{2}$, formed from reaction of iron with the alumina support as a significant intermediate phase generated in the reduction pre-treatment, and the enhancement of the stability of austenitic iron metal phases brought about by the presence of the second element. In the current work, using Mo XAFS and Fe Mössbauer spectroscopies, we are examining in detail the reactions and transformations of a $\mathrm{Fe}_{4.5} \mathrm{Mo}_{0.5} / \mathrm{Al}_{2} \mathrm{O}_{3}$ catalyst as a function of time under methane at $700^{\circ} \mathrm{C}$. Our aim is to relate the specific Fe and Mo speciation to the behavior and activity of the catalyst. The typical activity curve for the decomposition of hydrogen under these conditions peaks at between 1 and 2 hours and then slowly diminishes with time. Hence, we are especially interested in the identification of phases and reactions that are significant around this time interval.

Currently, we have obtained the necessary spectroscopic data and are in the process of analyzing them. It is clear that under methane at $700^{\circ} \mathrm{C}$, both iron and molybdenum undergo a relatively slow reduction. Whereas the ferric iron reduces to a ferrous phase (formation of hercynite via reaction of the iron with the alumina support) within the first hour, the formation of metal and carbide phases is much slower and the ferrous phase persists up to at least 16 hours. Over time however, the ferrous phase is replaced by increasing amounts of austenitic iron and iron carbide species (mostly cementite, $\mathrm{Fe}_{3} \mathrm{C}$ ). Also of note is the initial formation of a $\mathrm{Fe}_{2} \mathrm{Mo}$ alloy phase that appears to convert over time into an austenitic phase. Hence, the correlation with activity would appear to suggest that either the hercynite or the $\mathrm{Fe}_{2} \mathrm{Mo}$ phase is the active catalyst. However, more work is needed to confirm this finding and to determine which of the two phases is catalytic.

\section{Element-doped SAPO catalysts:}

In conjunction with Prof. James Guin and co-workers (Auburn University), XAFS and other synchrotron techniques will be used to characterize the metal-doped silica-aluminaphosphate (SAPO) materials that are being synthesized at Auburn University. These materials have structural features in common with zeolites and form similar three-dimensional cages with atom and molecule-sized cavities within the framework structures. There is currently much interest in introducing metal atoms and ions in these materials for the development of new catalytic materials for possible $\mathrm{C} 1$ chemistry applications. The materials we have received to date from Dr Guin and his group consist of various different SAPO catalysts into which one or 
more cation species, such as $\mathrm{Mn}, \mathrm{Co}$ and $\mathrm{Ni}$, have been introduced. Each of these materials has been examined at the appropriate K-shell X-ray absorption edge using XAFS spectroscopy.

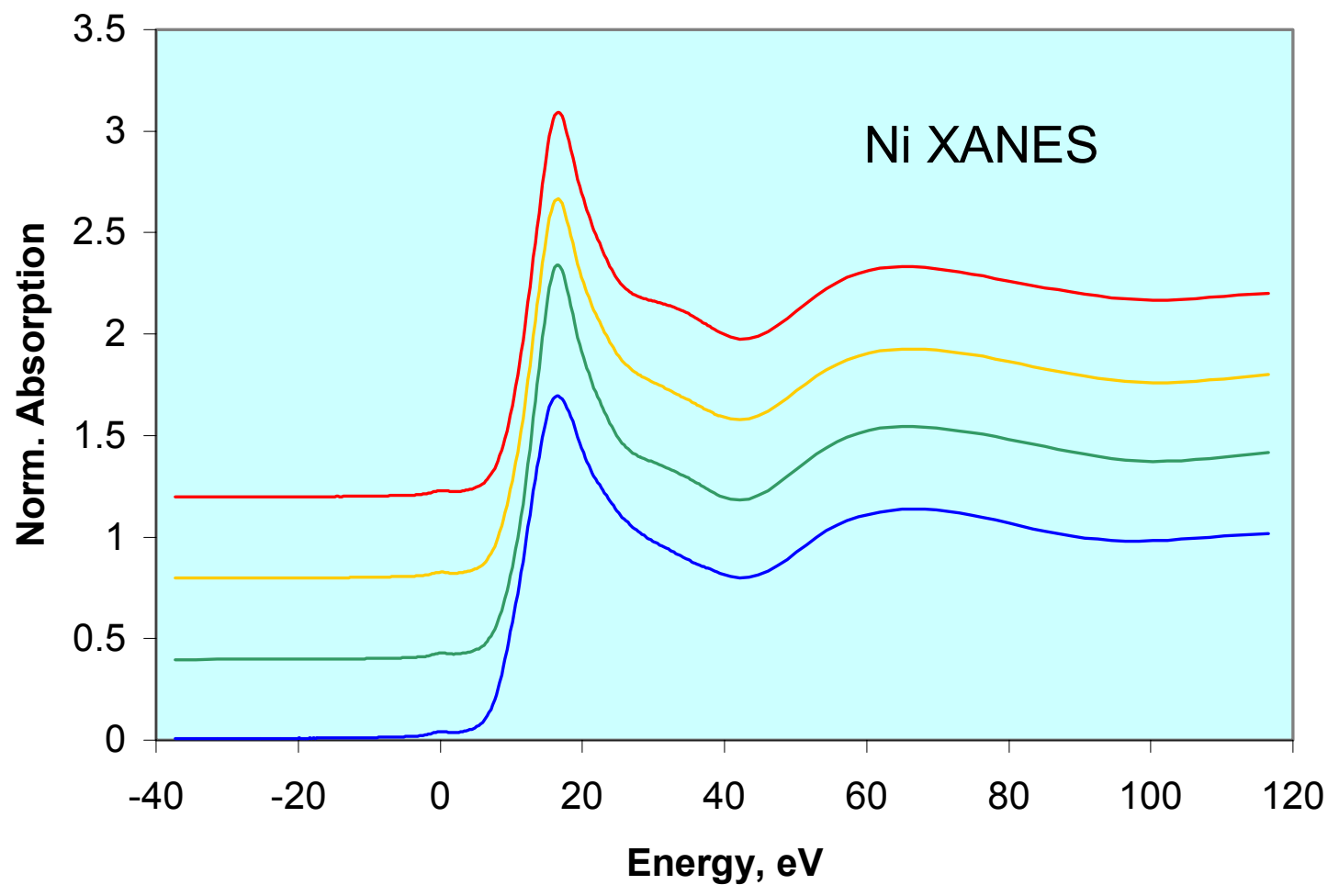

SAPO-44 — SAPO-17 - SAPO-34 - SAPO-18

Figure 1: Ni XANES spectra of various SAPO catalysts. The numerical designation for the catalysts indicates its structural type.

Figure 1 shows the Ni XANES spectra obtained for four different SAPO catalysts. The spectra exhibit only very minor differences from each other and look quite different from that reported previously for SAPO-5 [1]. In particular, the height of the small pre-edge peak at about $0 \mathrm{eV}$ is extremely small and incompatible with tetrahedrally bound $\mathrm{Ni}^{2+}$ reported for $\mathrm{Ni}$ in SAPO-5 and SAPO-34 [1]. This suggests that the $\mathrm{Ni}^{2+}$ in the catalysts prepared at Auburn may not be contained in the framework structure, but in some other centro-symmetric site. Other samples of Ni-doped SAPO-34 yield a Ni XANES spectrum that ressembles that of $\mathrm{NiAl}_{2} \mathrm{O}_{4}$. The Co XANES spectra for Co-doped SAPO materials look similar to the Ni XANES of Nidoped SAPO materials shown in Figure 1, whereas the Mn XANES spectra for the Mn-doped SAPO phases look quite different. Indeed the two Mn-doped SAPO materials exhibit significant differences. Clearly, there is a need to systematize this information and relate it to differences in the synthesis of these materials. Additional experiments are planned on these materials, not only with the XAFS technique, but also with synchrotron small-angle scattering methods.

Investigation of $\mathrm{Co}$ and Fe-doped silica xerogel catalysts:

In conjunction with Prof. Eyring and co-workers (U. of Utah), Co XAFS and Fe Mossbauer studies have been initiated of metal-doped silica xerogel catalyst materials that are being synthesized at the University of Utah. The only sample examined so far, a silica aerogel 
doped with a major amount of iron and a lesser amount of cobalt was examined by both Mössbauer and Co XAFS spectroscopies. Both techniques indicate that almost all of both elements are in the metallic state. About 5\% of the iron was identified by Mössbauer spectroscopy as being in the form of an iron silicate $\left(\mathrm{Fe}_{2} \mathrm{SiO}_{4}\right)$. The Mössbauer parameters for the iron metal indicate that the Co is also substituted in the same metal phase (Figure 2). Additional work is planned on similar materials.

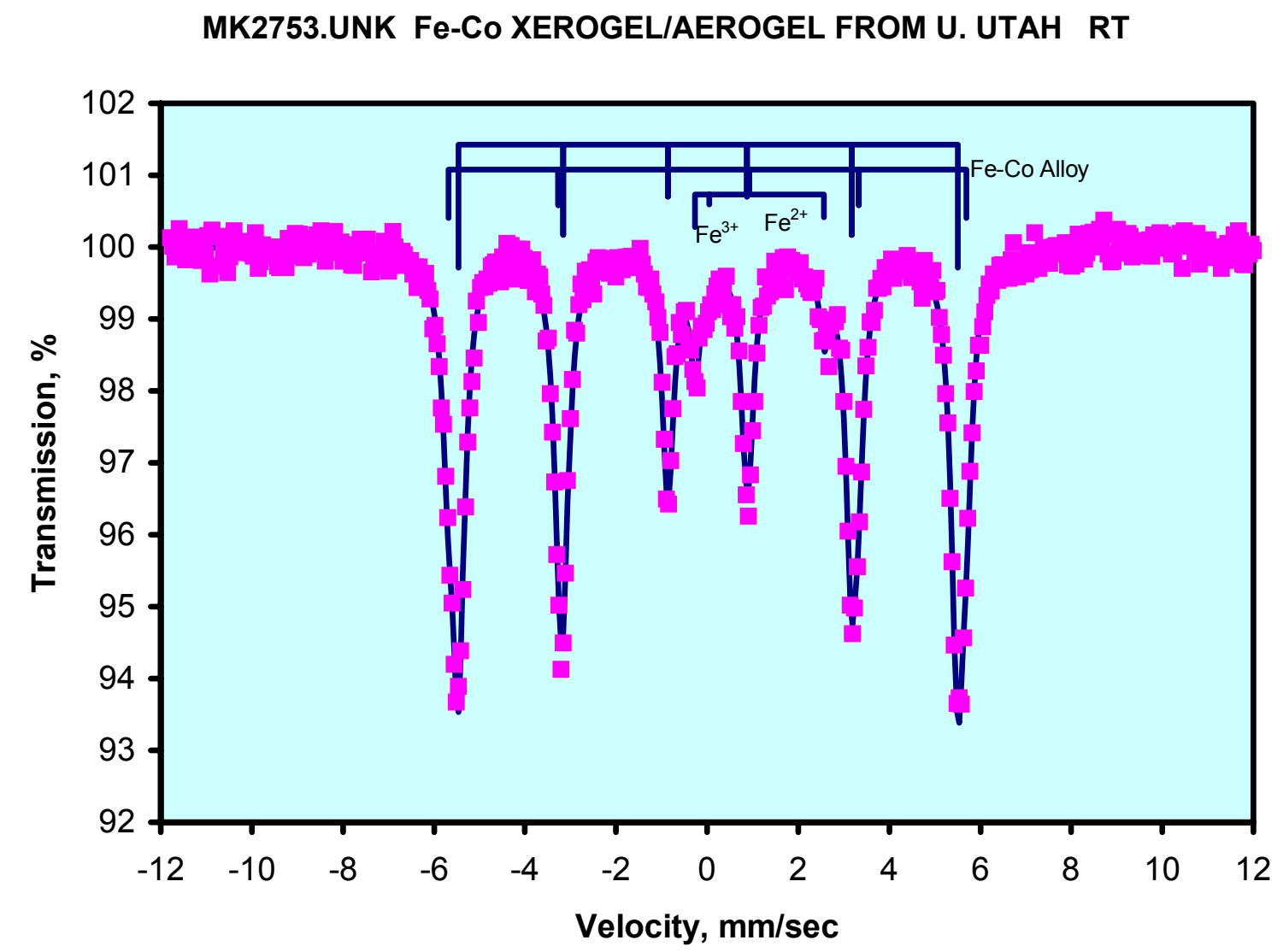

Figure 2: Mössbauer spectrum of a Co-Fe xerogel prepared at the University of Utah. 


\section{Science behind Catalysis in C1 Reactions: Catalyst characterization and determination of active species \\ M. S. Seehra, Physics Department, West Virginia University}

\section{$\underline{\text { Objectives }}$}

The objectives under this task are to characterize the structural and electronic properties of the catalysts used for converting $\mathrm{C} 1$ feedstocks into ultraclean liquid transportation fuels and high value chemicals, and for the efficient production of hydrogen from syngas, hydrocarbons and coals. The measured properties of the catalysts are then correlated with the distributions of the products in an effort to determine the mechanisms of the reactions and to determine the efficiency of a particular catalyst.

\section{Summary of Results}

During this reporting period, our efforts were concentrated on investigations of the following systems of catalysts:

$\underline{\mathrm{M} / \mathrm{Fe} / \mathrm{Al}_{2}} \underline{\mathrm{O}}_{3}(\mathrm{M}=\mathrm{Ni}, \mathrm{Mo}, \mathrm{Pd})$ catalysts for $\mathrm{CH}_{4} \underline{\text { to }}_{2} \underline{\mathrm{H}}_{2}$ conversion:

In this project, carried out in collaboration with the Huffman group at Kentucky, we investigated $0.5 \% \mathrm{M} / 4.5 \% \mathrm{Fe} / \mathrm{Al}_{2} \mathrm{O}_{3}(\mathrm{M}=\mathrm{Ni}, \mathrm{Mo}, \mathrm{Pd})$ catalysts used for producing $\mathrm{H}_{2}$ from $\mathrm{H}_{4}$ at $700^{\circ} \mathrm{C}$. X-ray diffraction (XRD) at $300 \mathrm{~K}$ and electron magnetic resonance (EMR) spectroscopy at $5 \mathrm{~K}$ to $300 \mathrm{~K}$ were employed to determine the different phases present before and after the reaction with $\mathrm{CH}_{4}$ at $700^{\circ} \mathrm{C}$ to produce $\mathrm{H}_{2}$. These studies showed that before the reaction, catalysts reduced at $700^{\circ} \mathrm{C}$ contain $\gamma-\mathrm{Al}_{2} \mathrm{O}_{3}$, elemental $\mathrm{Fe}$, iron oxides, and $\mathrm{Fe}^{3+}$ substituting for $\mathrm{Al}^{3+}$ in $\mathrm{Al}_{2} \mathrm{O}_{3}$. Also, the presence of $\mathrm{Ni}$, Mo and $\mathrm{Pd}$ was found to promote the reduction of iron oxides to Fe at lower temperatures. After the reaction with $\mathrm{CH}_{4}$, elemental Fe is considerably lowered and the presence of $\mathrm{Fe}_{3} \mathrm{C}$ and graphitic nanotubes is observed, following the reaction $3 \mathrm{Fe}+\mathrm{CH}_{4} \rightarrow \mathrm{Fe}_{3} \mathrm{C}+2 \mathrm{H}_{2}$, although there are no significant changes in the concentrations of iron oxides and $\mathrm{Fe}^{3+} / \mathrm{Al}_{2} \mathrm{O}_{3}$. Since the amounts of $\mathrm{Fe}$ and $\mathrm{Fe}_{3} \mathrm{C}$ are relatively small, the above equation cannot be the only source of $\mathrm{H}_{2}$. Perhaps the $\mathrm{Fe}^{3+} / \mathrm{Al}_{2} \mathrm{O}_{3}$ and the iron oxides which remain unchanged in the reaction, are the dominant catalysts. Details of this work are presented in a forthcoming paper [1].

Methanol to Olefins conversion over doped SAPO-34 molecular sieves:

At Auburn University, Prof. Guin's group has synthesized SAPO-34 molecular sieves modified with the transition metals $\mathrm{Co}, \mathrm{Mn}$ and $\mathrm{Ni}$ for the methanol to olefins conversion. We used $\mathrm{x}$-ray diffraction at $300 \mathrm{~K}$ and magnetic measurements from $5 \mathrm{~K}$ to $300 \mathrm{~K}$ to determine the electronic state of the transition metals and their concentrations, and whether the metal ions are incorporated into the SAPO framework or not. From these studies, MnSAPO-34 was found to be the best catalyst based on catalyst lifetime. In the case of Ni-SAPO-34, unusually high amounts of methane were observed in the products due to the presence of Ni nanoparticles outside the SAPO framework. Further details of this work are given in a forthcoming paper prepared in collaboration with Guin et al [2].

Xerogel supported Cobalt catalysts for Fischer-Tropsch synthesis:

Xerogel supported Co-catalysts are being synthesized by Prof. Eyring's group at Utah and investigated for F-T activity. We are investigating these catalysts using X-ray diffraction and 
magnetic measurements to determine the electronic state of cobalt before and after the reactions. Our studies show that depending on the Co loading, both elemental $\mathrm{Co}$ and $\mathrm{CoO}$ are present in a core-shell structure. Further investigations are underway and we expect to present details of these studies in a future paper, in collaboration with Eyring et al.

Structural disorder in nanoparticle systems:

Catalysts are most active when their particle size is reduced to nm scale because of the resulting high surface area/volume ratio at nano dimensions. What is the structural order at $\mathrm{nm}$ scales? By a detailed analysis of the intensities of the x-ray diffraction lines and thermal diffused scattering (TDS) in the $\mathrm{CuO}$ nanoparticle system in the size range of 6 to $50 \mathrm{~nm}$, we have determined that with the decrease in particle size, both the percentage of TDS and the DebyeWaller factor $\mathrm{W}$ increase at the expense of elastic Bragg scattering. This leads to the conclusion that structural disorder in nanoparticles increases with decreases in particle size. These results are being prepared for publication and the implications of these results for catalysis are being examined.

$\underline{\text { Publications }}$

1. A. Punnoose, N. Shah, G. P. Huffman and M. S. Seehra, "X-ray diffraction and electron magnetic resonance studies of $\mathrm{M} / \mathrm{Fe} / \mathrm{Al}_{2} \mathrm{O}_{3}\left(\mathrm{M}=\mathrm{Ni}\right.$, Mo, and $\mathrm{Pd}$ ) catalysts for $\mathrm{CH}_{4}$ to $\mathrm{H}_{2}$ conversion," Fuel Processing technology (accepted for publication).

2. D. R. Dubois, D. L. Obrzut, J. Liu, J. Thundimadathil, P. Adekkanattu, J. A. Guin, A. Punnoose and M. S. Seehra, "Conversion of methanol to olefins over cobalt, manganese and nickel incorporated SAPO-34 molecular sieves," Fuel Processing Technology (accepted for publication).

1. N. Shah, N.; Panjala, D.; Huffman G. P. Energy \& Fuels, 15(6) (2001) 1528-34.

2. For example, US patents 5763725 and 5990370.

3. For example, US patents 5759946, 63555854, 6417422 and 6436871; World patent 9633149A1.

4. S.A.R. Mulla, O.V. Buyevskaya, M. Baerns; Applied Catalysis A, 226, (2002), 73-78.

5. M.A. Banares; Catalysis Today, 51 (1999), 319-348.

6. K. Venkataraman, J. M. Redenius, L. D. Schmidt; Chemical Engineering Science, 51, (2002), 2335-2343.

7. Y.Xu, V.C. Corberan; Progress in Natural Science, 10(1), (2000), 22-26.

${ }^{8}$. F. Solymosi, R. Nameth; Catalysis Letters, 62, (1999), 197-200.

9 . For example, US patents 5658452 and 5723707. 